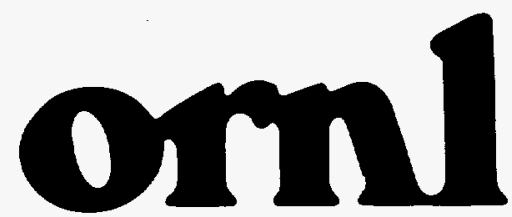

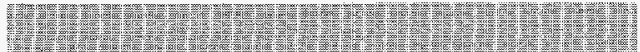

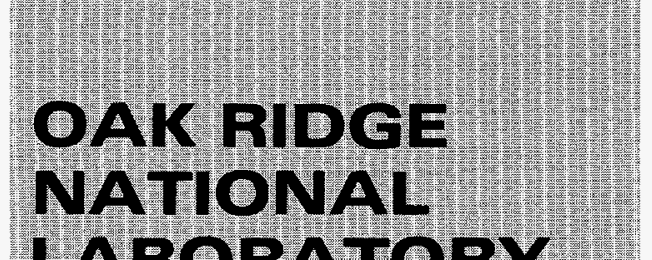

LABORATORY

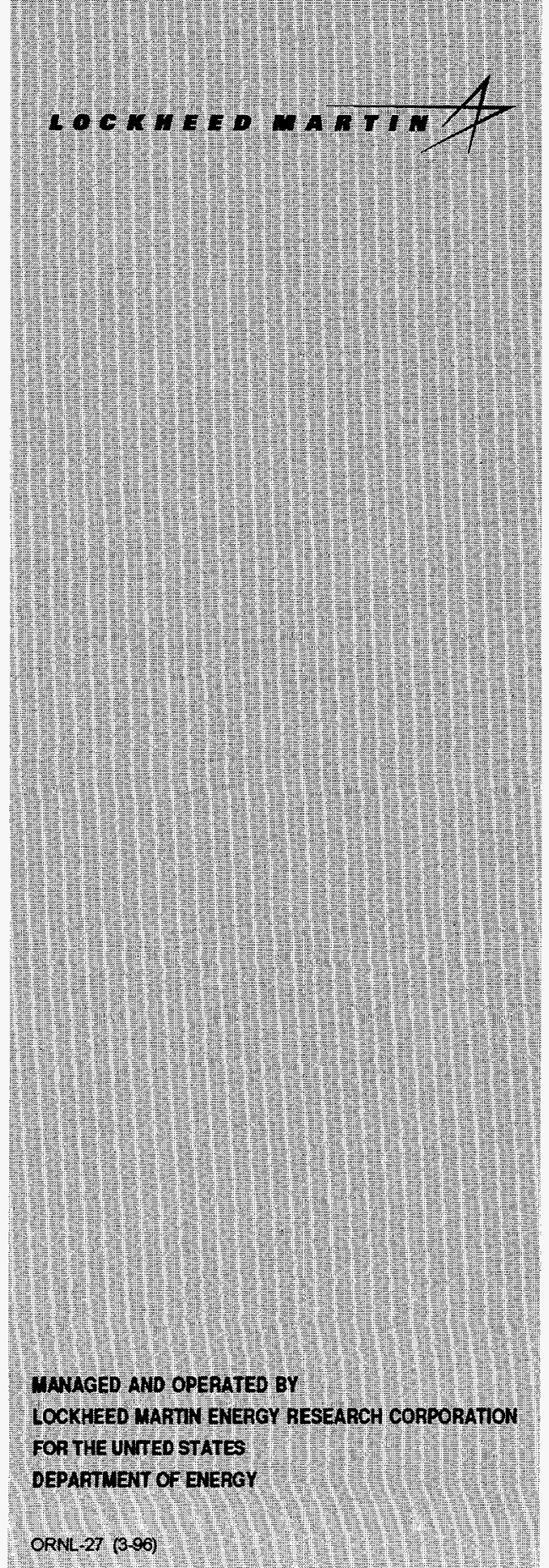

\section{WET-FILAMENT WINDING FABRICATION OF THICK CARBON FIBER/POLYCYANATE RESIN COMPOSITE}

\author{
B. J. Frame \\ Engineering Technology Division \\ Oak Ridge National Laboratory
}

\author{
W. G. Dodge \\ Y-12 Development \\ Oak Ridge Y-12 Plant
}

June 1997

June 1997 


\section{DESCLAMIER}

Portions of this document moy be illegible in electronic image prodnets. Images are produced from the best available original docoment 


\title{
WET-FILAMENT WINDING FABRICATION OF THICK CARBON FIBER/POLYCYANATE RESIN COMPOSITE
}

\author{
B. J. Frame \\ Engineering Technology Division \\ Oak Ridge National Laboratory \\ W. G. Dodge \\ Y-12 Development \\ Oak Ridge Y-12 Plant
}

June 1997

Prepared by the

Oak Ridge National Laboratory

Oak Ridge, Tennessee 37831-8048

\author{
Managed by \\ LOCKHEED MARTIN \\ ENERGY RESEARCH CORPORATION \\ for the \\ U.S. DEPARTMENT OF ENERGY \\ under contract DE-AC05-96OR22464
}




\section{TABLE OF CONTENTS}

LIST OF FIGURES $\ldots \ldots \ldots \ldots \ldots \ldots \ldots \ldots \ldots \ldots \ldots \ldots \ldots \ldots \ldots \ldots \ldots \ldots \ldots \ldots \ldots \ldots$ iii

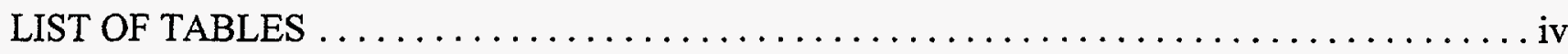

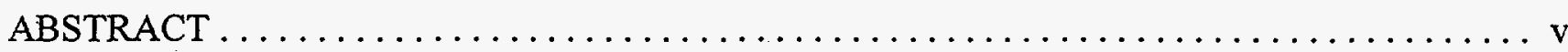

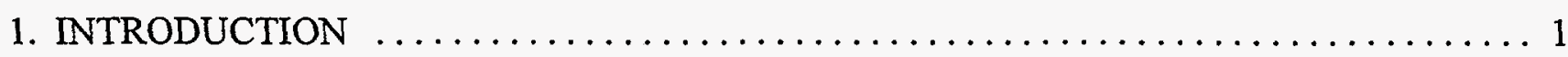

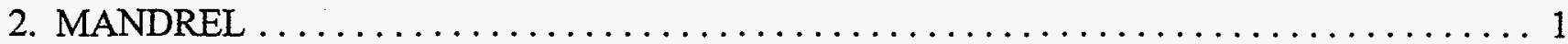

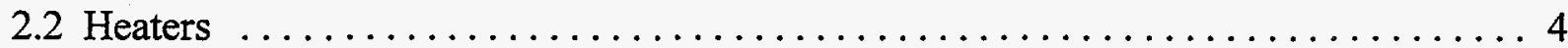

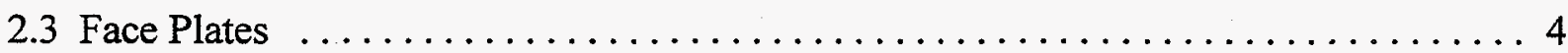

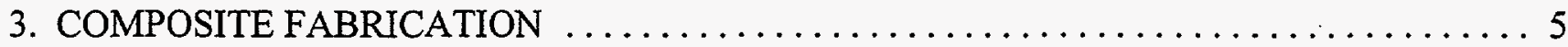

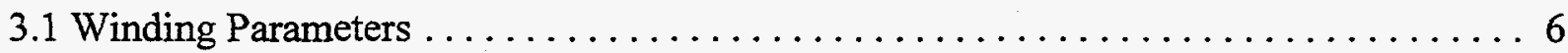

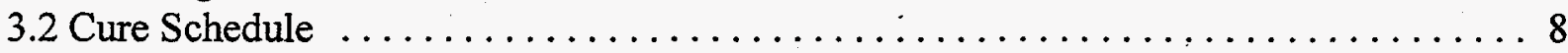

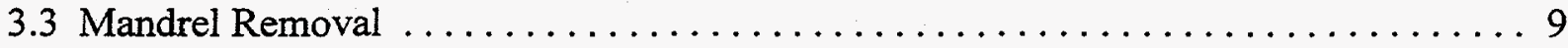

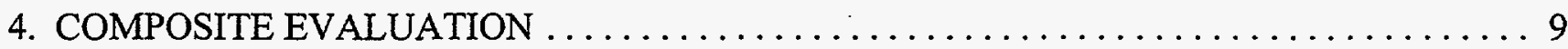

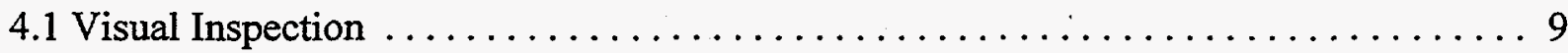

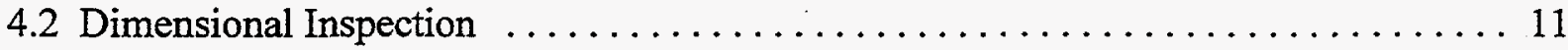

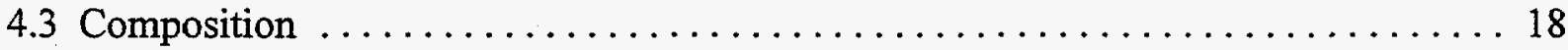

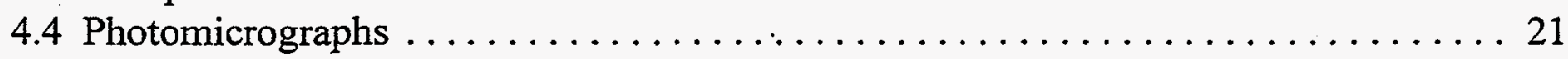

5. MANDREL POST-FABRICATION INSPECTION ...................... 29

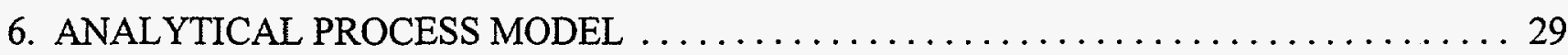

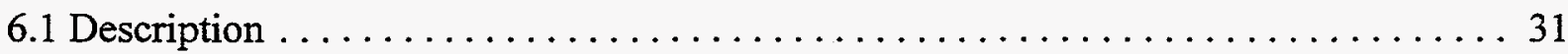

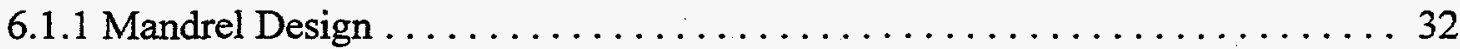

6.1.2 Mandrel Removal . . . . . . . . . . . . . . . . . . . . . . 32

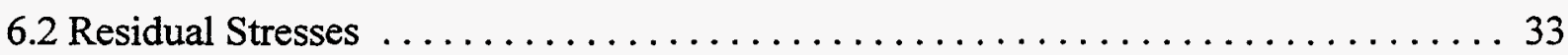

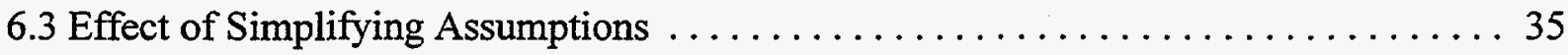

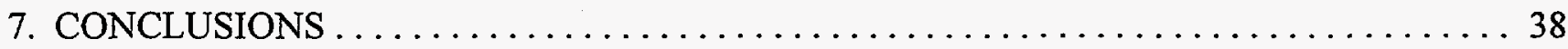

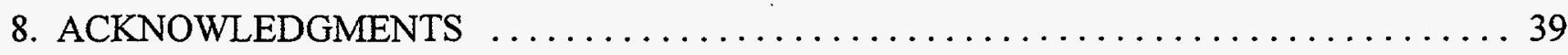

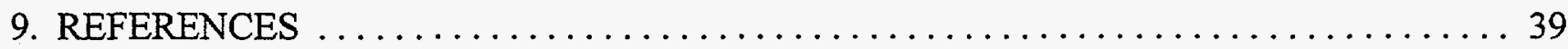

APPENDIX A. Analytical process model applied to T1000G/RS-14 thick cylinder fabrication .. A1 


\section{LIST OF FIGURES}

Figure $2.1-1$. Schematic of internally heated steel mandrel $\ldots \ldots \ldots \ldots \ldots \ldots \ldots \ldots \ldots$

Figure $3.1-1$. Wet-filament winding the thick T1000G/RS-14 cylinder $\ldots \ldots \ldots \ldots \ldots \ldots 7$

Figure 3.3-1. Thick T1000G/RS-14 cylinder and internally heated steel mandrel $\ldots \ldots \ldots \ldots 10$

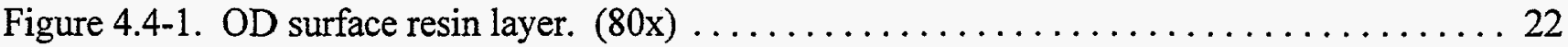

Figure 4.4-2. Composite fiber packing near OD. $(80 \mathrm{x}) \ldots \ldots \ldots \ldots \ldots \ldots \ldots \ldots \ldots \ldots \ldots \ldots \ldots$

Figure 4.4-3. Composite fiber packing (random location). (200x) $\ldots \ldots \ldots \ldots \ldots \ldots \ldots$

Figure 4.4-4. Composite fiber packing (random location). (1000x) $\ldots \ldots \ldots \ldots \ldots \ldots \ldots \ldots$

Figure 4.4-5. Composite fiber packing near ID. $(200 \mathrm{x}) \ldots \ldots \ldots \ldots \ldots \ldots \ldots \ldots \ldots \ldots \ldots \ldots \ldots \ldots \ldots$

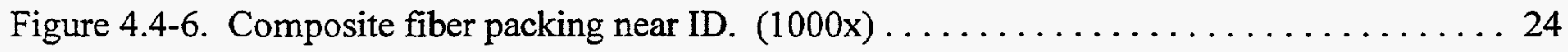

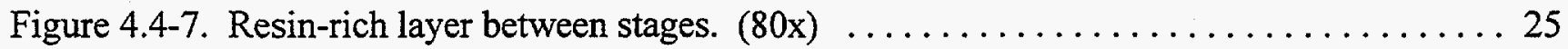

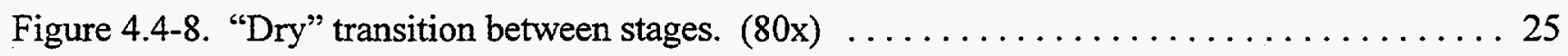

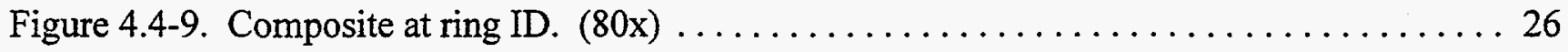

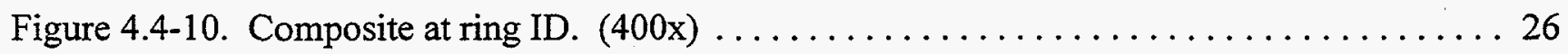

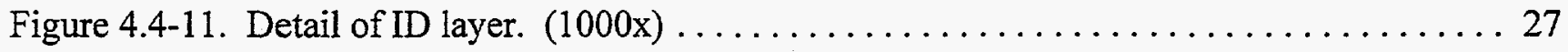

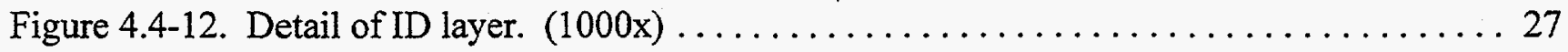

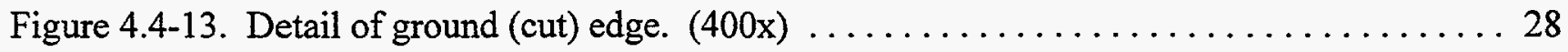

Figure 6.3-1. Axi-symmetric, finite element model of mandrel and composite during processing . 37 


\section{LIST OF TABLES}

Table 4.2-1. T1000G/RS-14 Ring no. 1 - ID TIR (in.) ...................... 12

Table 4.2-2. T1000G/RS-14 Ring no. 1 - OD TIR (in.) ....................... 13

Table 4.2-3. T1000G/RS-14 Ring no. 1 - wall thickness (in.) $\ldots \ldots \ldots \ldots \ldots \ldots \ldots \ldots \ldots$

Table 4.2-4. T1000G/RS-14 Ring no. 2 - ID TIR (in.) ....................... 15

Table 4.2-5. T1000G/RS-14 Ring no. 2 - OD TIR (in.) $\ldots \ldots \ldots \ldots \ldots \ldots \ldots \ldots \ldots \ldots \ldots \ldots \ldots$

Table 4.2-6. T1000G/RS-14 Ring no. 2 - wall thickness (in.) $\ldots \ldots \ldots \ldots \ldots \ldots \ldots \ldots \ldots$

Table 4.3-1. T1000G/RS-14 Ring no. 1 - composition data ..................... 19

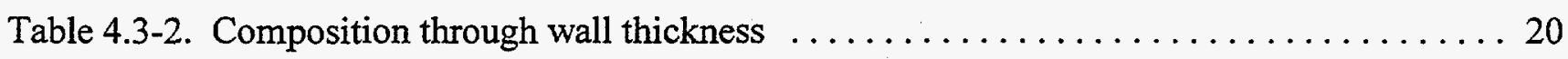

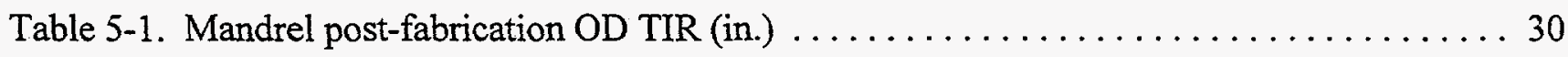

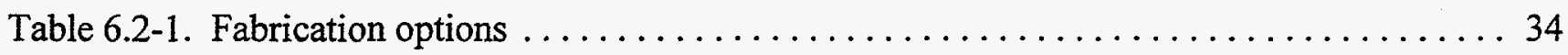




\begin{abstract}
Polycyanate resins offer advantages as composite matrices because of their high thermal stability, low outgassing, low water absorption and radiation resistance. This report describes the fabrication of a thick (nominal $1 \mathrm{in}$.) hoop-wound composite cylinder that is manufactured by the wet-filament winding method using Toray T1000G carbon fiber and YLA RS-14 polycyanate resin as the constituent materials. An analytical model used to evaluate the fabrication process, estimate composite residual stresses and provide input toward mandrel design is presented and the construction of the mandrel used to wet-wind the cylinder is described. The composite cylinder quality is evaluated by dimensional inspection and measurements of density and composition.
\end{abstract}




\section{INTRODUCTION}

The Oak Ridge National Laboratory (ORNL) and the Oak Ridge Center for Manufacturing Technology (ORCMT)* are involved in the development of affordable composite structures for military, aerospace and transportation applications. As part of this continuing activity, ORNL/ORCMT evaluate new materials and combinations of materials for use in such applications as pressure vessels, flywheel energy storage systems and aircraft structures.

This report documents the fabrication of a thick (nominal $1 \mathrm{in}$.), composite cylinder entirely wetwound from Toray T1000G carbon fiber and YLA RS-14 polycyanate resin. The objective of this study was to demonstrate a viable manufacturing method as well as to verify the quality of the composite. This work is a continuation of process development work previously performed and reported by ORNL/ORCMT ${ }^{1,2}$.

Included in this report are details of the fabrication process as well as the results of the dimensional inspection, photomicroscopy density, and composition measurements performed on the composite. An analytical model used to evaluate the fabrication process, estimate composite residual stresses and provide input toward mandrel design is presented and the construction of the mandrel used to wet-wind the cylinder is described.

\section{MANDREL}

The T1000G/RS-14 composite cylinder in this study was wet-wound on an internally heated steel mandrel. This mandrel was designed and constructed by ORNL/ORCMT to provide capability to wet-wind thick (up to $1 \mathrm{in}$.) carbon fiber/polycyanate composites. A summary of the mandrel design and features is provided in this section.

\subsection{Mandrel Design and Construction}

When a metal mandrel and hoop-wound composite are brought to an elevated process (cure) temperature, there is a mismatch in the coefficient of thermal expansion (CTE) between the two.

\footnotetext{
*The Oak Ridge Centers for Manufacturing Technology (ORCMT) is jointly managed by the Oak Ridge National Laboratory and Lockheed Martin Energy Systems.
} 
The carbon composite band's near-zero to slightly negative CTE and high modulus causes it to restrict the expansion of the mandrel. Depending on the maximum cure temperature and the thickness of the carbon composite, it is possible to plastically deform the mandrel body. With rigid side faces, the mandrel becomes "hourglass" shaped. The consequences can be a composite inner diameter (ID) which conforms to the hourglass shape and possible difficulty sliding the composite over the rigid side faces and off the mandrel after cure.

Figure 2.1-1 is a schematic of the internally heated steel mandrel. It was designed to withstand the high compressive stresses that arise from the mismatch in the CTE's between the mandrel material and thick hoop-wound composite bands during elevated temperature postcure cycles.

The primary component of the mandrel is a cylindrical shell which was fabricated with a nominal 24 in. outer diameter (OD) and an overall length of 19 in. The shell is 1.25 in. thick and made of 4340 steel that has been heat treated to obtain a 300-330 Brinell hardness. The OD was flash chromed to prevent rusting and protect the surface. The mandrel OD concentricity met or exceeded the 0.0005 in. tolerance specified by the design.

The mandrel shell is supported at the ID by 1 in. steel end plates. The end plates slide into 1 in. wide $\times 1 / 8$ in. deep steps cut into the ID at each end of the shell. The step ID provides for a nominal $0.01 \mathrm{in}$. radial clearance with the OD of the end plates. The mandrel shafts are $4 \mathrm{in.} O D \times 5 / 8 \mathrm{in}$. wall thickness steel tubing welded to each end plate.

A center assembly consisting of a section of $14 \mathrm{in}$. pipe with flanges welded at each end acts as a tie-rod to hold the mandrel together. The end plates are bolted to the center assembly and press against the $1 / 8$ in. wide face of the step. Friction from the end plates pressing on the step face at the shell ID is sufficient to keep the shell from sliding during the winding operation. The intent is that the end plates not be rigidly mounted or welded to the mandrel shell so the mandrel body can be compressed uniformly as a cylinder along its length during cure, rather than "hour glassing" between rigid end supports. 


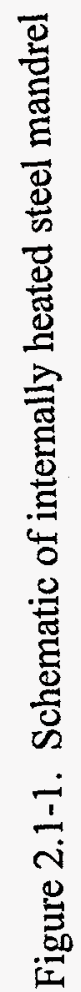
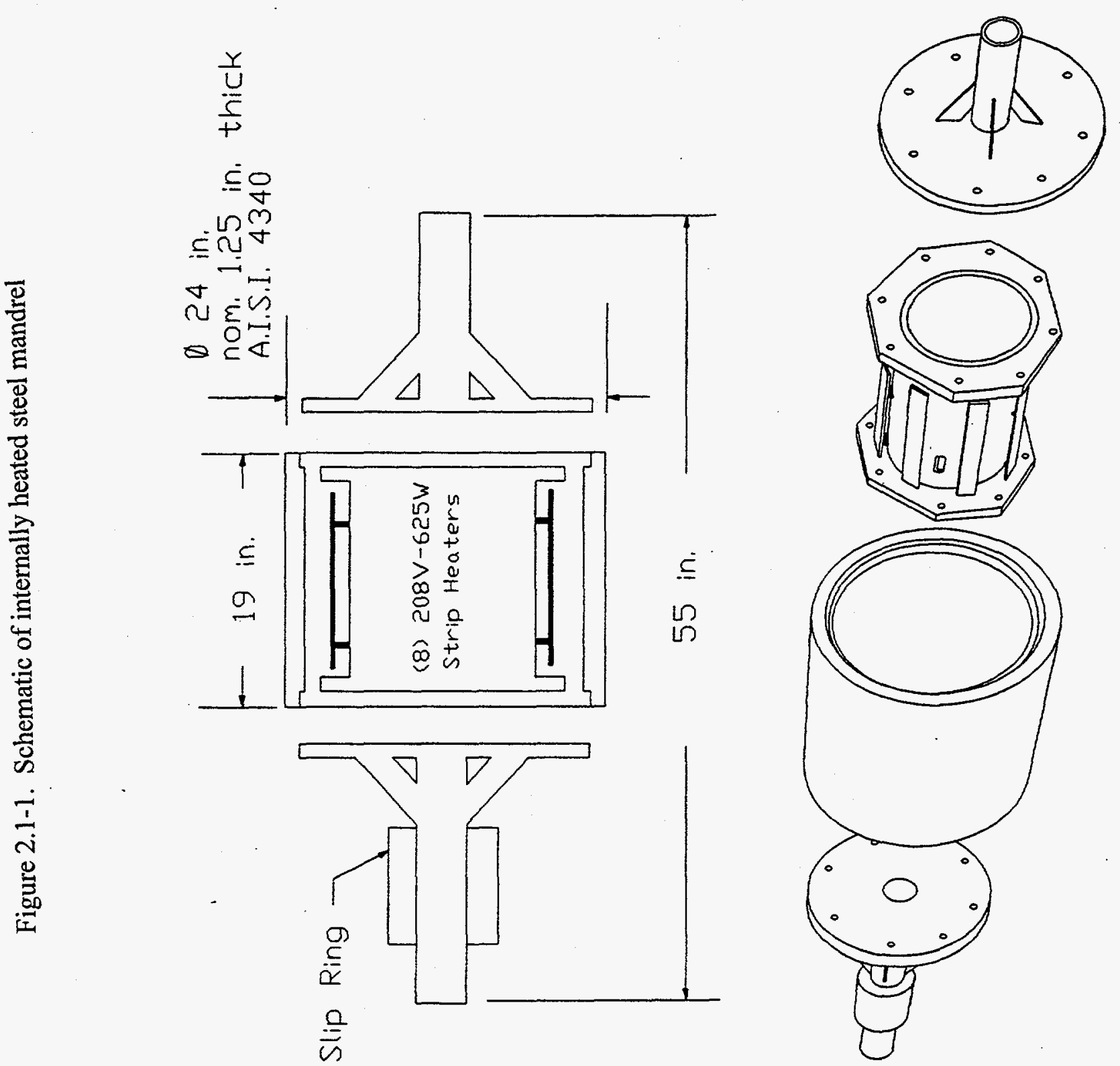


\subsection{Heaters}

The mandrel is internally heated to provide the necessary mandrel surface temperatures required to wet-wind polycyanate matrix composites. Heating is accomplished by an array of eight radiant heaters that are focused on the shell ID and that are mounted at equal distances around the center assembly. The heaters are wired through a slip ring so the mandrel can be heated while it is being rotated. Heater output is adjusted by a variac potentiometer to provide a specific mandrel temperature. Temperature control can be maintained nominally within $+/-5^{\circ} \mathrm{F}$ of a set point during winding.

A set of nominal 1/8 in. diameter $x 1$ in. deep holes were drilled into both side faces of the mandrel for the insertion of thermocouple probes so that accurate temperature measurements of the mandrel shell can be made. A set of four holes was drilled into each side face of the mandrel shell just below the OD surface and spaced 90 degrees apart from one another. Another set of holes was drilled into each side face near the mandrel shell ID. The mandrel shell OD and ID thermocouple holes are staggered 45 degrees apart from one another at each end of the mandrel.

As part of this study, temperature measurements were made periodically during the winding process by stopping the mandrel and inserting a thermocouple probe into the hole(s) to check the ID and OD surface temperatures at various locations on the mandrel. It is technically feasible, however, to make continuous shell temperature measurements during winding by wiring the thermocouple wire through the slip ring and to a temperature readout.

\subsection{Face Plates}

Aluminum face plates or "keeper" rings that bolt onto each end of the mandrel were fabricated. The face plates act as "stops" or dams when the fiber is wet-wound against them; they are to keep the composite layers from sliding horizontally along the length of the mandrel as the composite thickness increases. The intent was to reduce the amount of tapered scrap produced at the ends of the cylinder. 


\section{COMPOSITE FABRICATION}

This study is a continuation of process development work previously performed and reported by the ORNL/ORCMT ${ }^{1,2}$. It marks a departure from fabricating "thin" (less than $1 / 8$ in.) to "thick" (nominal $1 \mathrm{in.}$ ) carbon fiber/polycyanate resin composite.

There are several factors to consider when wet-winding thick composites. One is the need to balance the increased manufacturing time with the resin pot life. With epoxies, it is necessary to stop periodically to clean the winding equipment because the ever increasing viscosity of the resin coating the pulleys, contact surfaces, etc begins to tear and damage the fiber. Tests with RS-14 polycyanate resin show that its viscosity is stable at $170^{\circ} \mathrm{F}$ for 8 hour periods or longer so that pot life is less of a factor with this resin than for most epoxies.

Another consideration is the introduction of additional residual stresses into the composite which can impact performance, including increasing the potential for radial cracking. Residual stresses in thick composites are influenced by many factors. These include the mandrel wall thickness and $\mathrm{CTE}$, the mandrel temperature during various stages of the winding process, fiber tensioning, the amount of resin bleedout during and after winding, the resin gel time and temperature, the cure cycle, the composite wall thickness and the fiber content to name just a few.

ORNL/ORCMT has had good experience fabricating thick carbon fiber/epoxy matrix composites by stage curing after every $1 / 4$ in. or less wall thickness increment is wound. The winding and cure of multiple stages is theorized to reduce residual stresses in thick composites below those introduced by winding and curing the composite in one step. Residual stresses can arise after resin gelation has occurred and when the deformation of a composite layer during the cure process is restricted because the layer is confined by the presence of other layers above and below. Stage curing can reduce these residual stresses because the individual stage is free to deform without confinement from the outermost composite layers. This method was therefore judged to be a reasonable approach for fabricating the thick T1000G/RS-14 resin cylinder. The time to wind $1 / 4$ in. wall thickness increments also averages between 6 to 8 hours and is well within the accepted working life of the RS-14 polycyanate resin. 


\subsection{Winding Parameters}

The thick composite cylinder was hoop-wound with Toray T1000G fiber from Lot No. 614121 and YLA RS-14 polycyanate resin. The cylinder length wound between the two face plates was 18 in. Figure 3.1-1 is a view of the composite being wound on the internally heated steel mandrel. The process parameters and procedures used to wet-wind the cylinder were developed in previous studies with these materials ${ }^{1,2}$ and are summarized in this section.

The resin wet-out pot temperature was maintained between $170^{\circ}-175^{\circ} \mathrm{F}$ throughout the winding process. At these temperatures, the RS-14 resin has a viscosity of $150-100 \mathrm{cps}$ and can effectively impregnate the fiber bundle. In addition, all intermediate contact points between the wet-out pot and the mandrel were heated to reduce fuzzing and fiber breakage.

The T1000G was wound with $12 \mathrm{lbs}$ tension for the entire cylinder fabrication. Weighted steel compaction rollers were run over each hoop layer as it was applied at the mandrel to provide additional compaction of the fiber layer. This increases the fiber fraction and reduces the void level in the composite by squeezing excess resin and air to the surface.

ORNL/ORCMT experience has shown that hoop-wound polycyanate resin composites benefit from additional compaction passes to ensure that there is no excess resin in the composite. (In all hoopwound cylinders, excessive resin bleed out during the elevated temperature cure cycle can result in a loss of fiber tension on the inner hoop fiber windings and visible fiber wrinkling at the ID). Therefore, two additional compaction passes with the compaction rollers were applied after winding every 5-6 layer increment, accompanied by wiping the excess resin from the composite surface.

The internally heated steel mandrel and the composite surface were maintained between $195^{\circ}$ $210^{\circ} \mathrm{F}$ during winding. This is hotter than the $175^{\circ} \mathrm{F}$ temperature typically required with $\mathrm{RS}-14$ resin to ensure good fiber consolidation and resin bleedout at the mandrel. The mandrel/composite surface temperatures were increased in this fabrication to provide additional thermal expansion of the steel mandrel during winding which in turn would provide added clearance between the composite and the mandrel at room temperature. The intent was to facilitate mandrel removal after cure. 


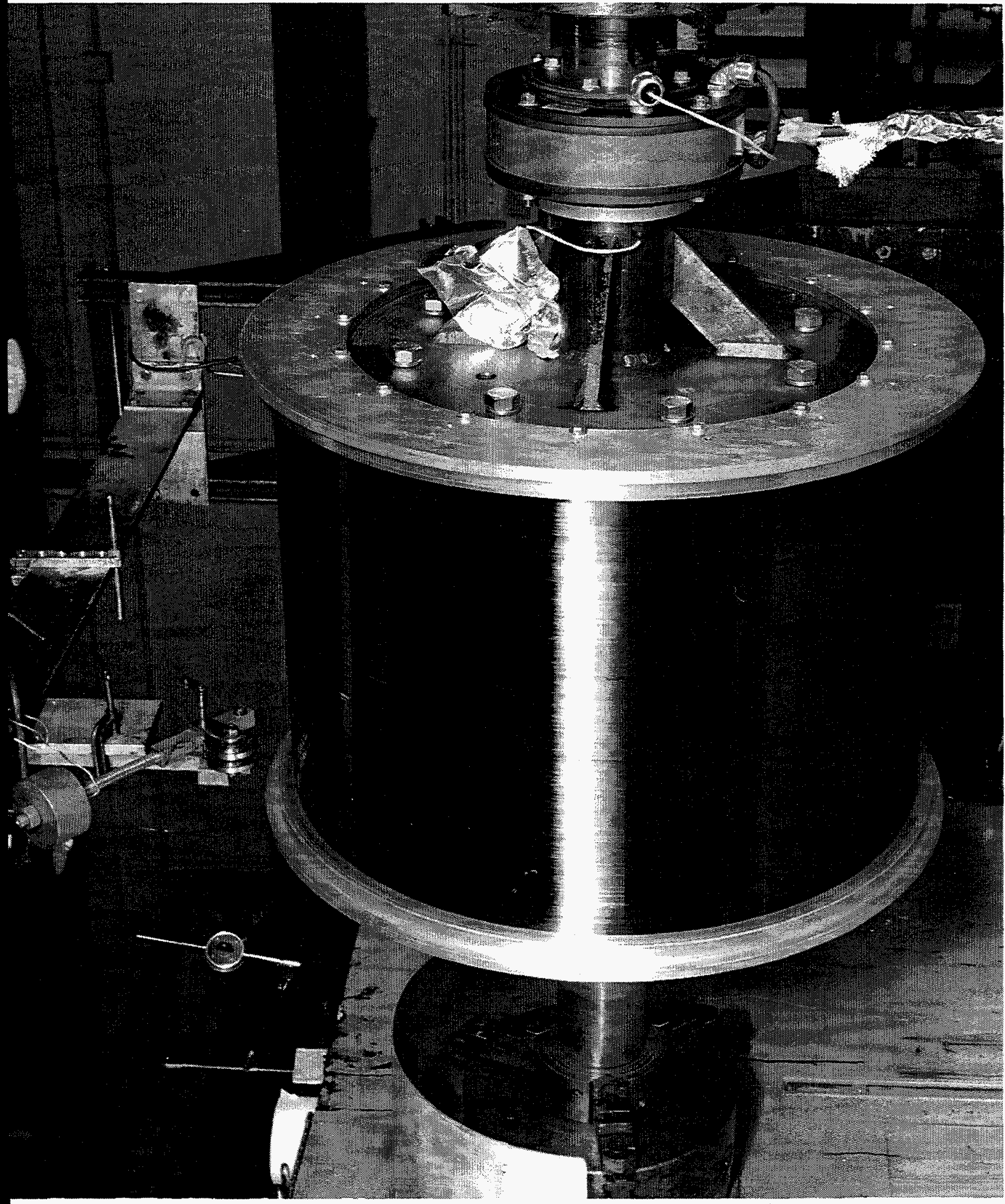

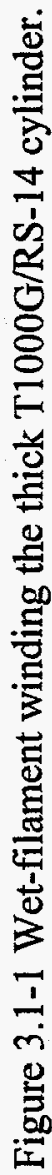


As the winding progressed, the thickening composite acted as an insulating layer and an external strip heater was required to maintain the composite surface temperature. The mandrel's internal heater assembly functioned at this point primarily to maintain the mandrel temperature and expansion so that there would be continuous contact with the composite ID.

One observation is that it requires a little practice and judgement to master the procedures that control the surface resin content of the intermediate stages and final composite OD. It is desirable that the intermediate stages be left with a relatively "dry" surface so that there will be no thick resin layers between stages. The adhesion of the subsequent stage that is wound over a dry surface is also believed to be better because the surface is "rough" rather than having a glossy resin finish. On the other hand, the final OD surface should have a sufficient resin layer to ensure that all fibers are adequately coated and protected.

The surface resin content can be influenced by adjusting the amount of resin left on the surface and in the underlying layers after winding, the surface temperature, and by the amount of time the part is allowed to rotate prior to initiating cure. Depending on these factors the surface resin remaining after winding is finished can (1) be absorbed into the composite during the cure cycle, making the surface dryer, (2) remain the same, or (3) increase due to resin bleedout during cure. Excess entrapped air in the underlying layers can also migrate outward during the cure cycle, leaving bubbles in the surface.

Fabrication of the thick T1000G/RS-14 cylinder provided four opportunities to practice adjusting the finished surface resin layer with this resin. The first stage experienced some localized resin bleedout during cure. The excess resin was sanded and degreased with acetone prior to winding the next stages. Adjustments were made to the final wipe/compaction passes so that the second and third stage surface resin contents were both dry and uniform. Sufficient resin was left on the surface of the fourth and final stage to yield a resin-rich finish for protecting the fibers at the composite OD.

\subsection{Cure Schedule}

The thick T1000G/RS-14 cylinder was wound in nominal $1 / 4$ in. thick increments per day over a 4 day period. Each $1 / 4$ in. increment, or stage, was precured by ramping at $2^{\circ} \mathrm{F} /$ minute to $380^{\circ} \mathrm{F}$ and holding at that temperature for 3 hours. Because RS-14 will not start to gel until a minimum 
temperature of $280^{\circ} \mathrm{F}$ is reached, the mandrel was rotated in the oven during the ramp to the precure temperature to prevent the composite sagging.

On the fourth day, after the last stage was wound, the composite was precured as described above and then immediately ramped at $1.5^{\circ} \mathrm{F} /$ minute to $520^{\circ} \mathrm{F}$ and postcured at this temperature for 5 hours.

\subsection{Mandrel Removal}

After cure, the mandrel and composite were allowed to cool back to room temperature. The mandrel was rotated from a horizontal to a vertical position and the keeper rings were removed. The mandrel was then lifted out of the composite cylinder without complications. A photograph of the thick T1000G/RS-14 cylinder adjacent to the internally heated steel mandrel after mandrel removal is shown in Figure 3.3-1.

\section{COMPOSITE EVALUATION}

The thick T1000G/RS-14 cylinder quality was evaluated by visual inspection, dimensional inspection, composition measurements, and microscopic examination of polished cross sections taken from the composite. The results are reported in the following sections.

\subsection{Visual Inspection}

Visual examination of the cylinder ID showed that it had no visible blisters or fiber wrinkling. There were some localized resin starved areas concentrated primarily near one end of the cylinder. These dry spots are on the order of one half to one layer ( 0.003 to 0.006 in.) deep.

The dry spots are believed to be the result of the $195^{\circ}-210^{\circ} \mathrm{F}$ mandrel temperature during winding. At these temperatures, the RS-14 resin viscosity was further reduced, while the mandrel's internal heat source maintained the reduced viscosity for an extended period. The net affect drove additional resin out of the ID layer.

Based on the fact that mandrel removal was not a problem, the corrective action in future fabrications is to reduce the mandrel surface temperature to the $175^{\circ}-180^{\circ} \mathrm{F}$ range. Extra resin can 


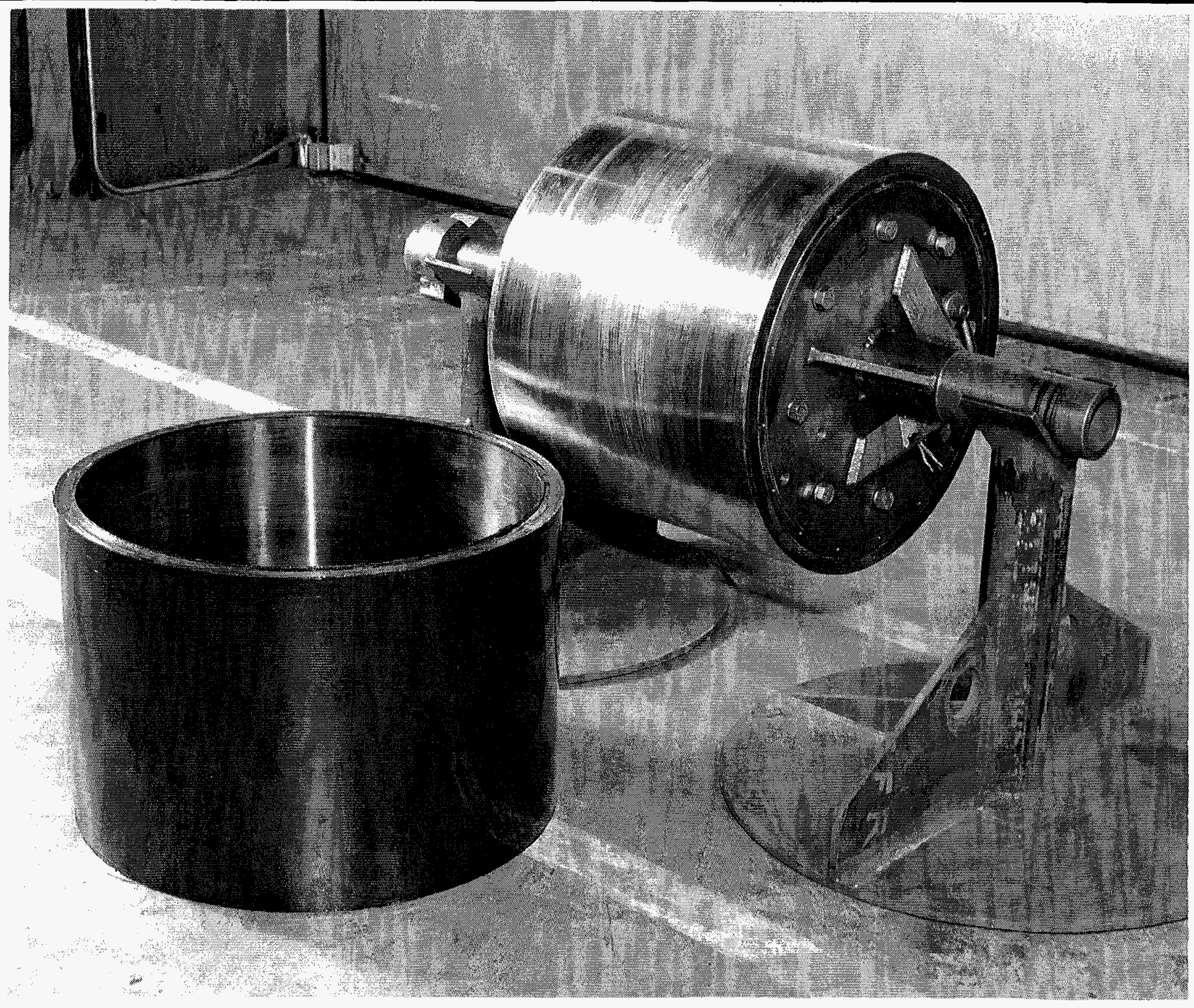

๘

Figure 3.3-1 Thick T1000G/RS-14 cylinder and internally heated steel mandrel. 
also be left at the ID during winding by not initiating the removal of excess surface resin until after the first 2-3 layers have been wound.

The visual appearance of the cylinder OD was typical for an all hoopwound carbon fiber composite. The OD surface resin layer was uniform and sufficiently thick to coat the OD fibers with between 0.003 to 0.005 in. of resin. There were no dry spots or large bubbles.

The T1000G/RS-14 cylinder was then supported at the ID on an aluminum arbor and chucked into a lathe. Runout measurements were taken using a dial indicator down the cylinder length. The measurements showed that the OD increased slightly from the cylinder edge to a point that was roughly $3.5 \mathrm{in.} \mathrm{down}$ the length of the cylinder. This OD taper was on the order of 1 degree, or $0.017 \mathrm{in} / \mathrm{in}$., and was the same at both ends. Although the face plates prevented the composite layers from sliding horizontally along the length of the mandrel during winding, the cylinder still had roughly 3.5 in. of tapered scrap at each end which needed to be removed. This left roughly an 11 in. length of uniform wall thickness cylinder for evaluation.

After the scrap had been removed two rings, each $3.5 \mathrm{in}$. wide, were cut from the cylinder remainder using a diamond-impregnated grinding wheel. Visual examination of the cut ends of the cylinder revealed that there were no delaminations or excess resin visible between the $1 / 4$ in. thick stages. The rings were then sent for dimensional inspection.

\subsection{Dimensional Inspection}

Table 4.2-1 through 4.2-6 summarize the dimensional inspection results made on a Zeiss Coordinate Measuring Machine of the two rings. Measurements for total indicated runout (TIR) at the ID and OD, and wall thickness were made at 10 degree intervals around the circumference of the ring at each of three separate axial locations along the ring height. The references "top" and "bottom" refer to measurements taken at a fixed 0.25 in. distance from each cut edge of the ring. "Middle" refers to measurements taken at a position midway between the two edges.

The results show that the ID TIR for Ring Nos. 1 and 2 are 0.0028 in. and 0.0032 in. respectively. The ID TIR is higher than the $0.0005 \mathrm{in}$. concentricity of the as-manufactured mandrel. This indicates there is either some deformation of the mandrel during fabrication and/or relaxation in the composite ring when it is no longer supported at the ID. 
Table 4.2-1. T1000G/RS-14 Ring no. 1 - ID TIR (in.)

\begin{tabular}{|c|c|c|c|}
\hline Degrees & Top & Middle & Bottom \\
\hline$\overline{0}$ & 0.0007 & 0.0013 & 0.0004 \\
\hline 10 & 0.0010 & 0.0016 & 0.0008 \\
\hline 20 & 0.0013 & 0.0020 & 0.0012 \\
\hline 30 & 0.0017 & 0.0023 & 0.0015 \\
\hline 40 & 0.0019 & 0.0026 & 0.0017 \\
\hline 50 & 0.0020 & 0.0027 & 0.0019 \\
\hline 60 & 0.0020 & 0.0028 & 0.0020 \\
\hline 70 & 0.0019 & 0.0027 & 0.0020 \\
\hline 80 & 0.0019 & 0.0026 & 0.0018 \\
\hline 90 & 0.0016 & 0.0024 & 0.0016 \\
\hline 100 & 0.0013 & 0.0021 & 0.0013 \\
\hline 110 & 0.0010 & 0.0018 & 0.0010 \\
\hline 120 & 0.0007 & 0.0015 & 0.0007 \\
\hline 130 & 0.0005 & 0.0013 & 0.0005 \\
\hline 140 & 0.0004 & 0.0011 & 0.0003 \\
\hline 150 & 0.0004 & 0.0011 & 0.0002 \\
\hline 160 & 0.0006 & 0.0012 & 0.0003 \\
\hline 170 & 0.0008 & 0.0014 & 0.0004 \\
\hline 180 & 0.0009 & 0.0016 & 0.0006 \\
\hline 190 & 0.0012 & 0.0017 & 0.0007 \\
\hline 200 & 0.0014 & 0.0020 & 0.0010 \\
\hline 210 & 0.0015 & 0.0020 & 0.0011 \\
\hline 220 & 0.0016 & 0.0022 & 0.0013 \\
\hline 230 & 0.0017 & 0.0024 & 0.0015 \\
\hline 240 & 0.0018 & 0.0026 & 0.0017 \\
\hline 250 & 0.0019 & 0.0027 & 0.0019 \\
\hline 260 & 0.0019 & 0.0027 & 0.0019 \\
\hline 270 & 0.0018 & 0.0026 & 0.0019 \\
\hline 280 & 0.0016 & 0.0024 & 0.0017 \\
\hline 290 & 0.0013 & 0.0021 & 0.0014 \\
\hline 300 & 0.0009 & 0.0017 & 0.0009 \\
\hline 310 & 0.0006 & 0.0014 & 0.0005 \\
\hline 320 & 0.0004 & 0.0011 & 0.0002 \\
\hline 330 & 0.0003 & 0.0009 & 0.0001 \\
\hline 340 & 0.0002 & 0.0009 & 0.0000 \\
\hline 350 & 0.0004 & 0.0010 & 0.0002 \\
\hline
\end{tabular}

TIR (108 places): $\quad 0.0028$ 
Table 4.2-2. T1000G/RS-14 Ring no. 1 - OD TIR (in.)

\begin{tabular}{|c|ccc|}
\hline Degrees & Top & Middle & Bottom \\
\hline \hline 0 & 0.0023 & 0.0028 & 0.0032 \\
10 & 0.0026 & 0.0035 & 0.0028 \\
20 & 0.0025 & 0.0026 & 0.0026 \\
30 & 0.0029 & 0.0022 & 0.0010 \\
40 & 0.0020 & 0.0021 & 0.0006 \\
$\mathbf{5 0}$ & 0.0014 & 0.0006 & 0.0009 \\
60 & 0.0000 & 0.0002 & 0.0006 \\
70 & 0.0015 & 0.0013 & 0.0015 \\
80 & 0.0024 & 0.0005 & 0.0015 \\
90 & 0.0022 & 0.0015 & 0.0018 \\
100 & 0.0011 & 0.0010 & 0.0019 \\
110 & 0.0022 & 0.0006 & 0.0017 \\
120 & 0.0022 & 0.0010 & 0.0029 \\
130 & 0.0030 & 0.0024 & 0.0029 \\
140 & 0.0023 & 0.0024 & 0.0031 \\
150 & 0.0015 & 0.0020 & 0.0029 \\
160 & 0.0017 & 0.0026 & 0.0029 \\
170 & 0.0029 & 0.0028 & 0.0031 \\
180 & 0.0024 & 0.0019 & 0.0031 \\
190 & 0.0030 & 0.0024 & 0.0033 \\
200 & 0.0022 & 0.0015 & 0.0032 \\
210 & 0.0013 & 0.0018 & 0.0025 \\
220 & 0.0017 & 0.0018 & 0.0027 \\
230 & 0.0028 & 0.0027 & 0.0034 \\
240 & 0.0027 & 0.0030 & 0.0037 \\
250 & 0.0040 & 0.0020 & 0.0030 \\
260 & 0.0024 & 0.0012 & 0.0022 \\
270 & 0.0043 & 0.0021 & 0.0032 \\
280 & 0.0035 & 0.0042 & 0.0034 \\
290 & 0.0051 & 0.0038 & 0.0050 \\
300 & 0.0039 & 0.0032 & 0.0028 \\
310 & 0.0043 & 0.0037 & 0.0040 \\
320 & 0.0051 & 0.0046 & 0.0045 \\
330 & 0.0049 & 0.0058 & 0.0052 \\
340 & 0.0040 & 0.0048 & 0.0054 \\
350 & 0.0031 & 0.0037 & 0.0038 \\
\hline & & & \\
\hline
\end{tabular}

TIR (108 places): $\quad 0.0058$ 
Table 4.2-3. T1000G/RS-14 Ring no. 1 - wall thickness (in.)

\begin{tabular}{|c|c|c|c|c|}
\hline Degrees & Top & Middle & Bottom & Average \\
\hline 0 & 1.0106 & 1.0117 & 1.0112 & 1.0112 \\
\hline 10 & 1.0112 & 1.0127 & 1.0112 & 1.0117 \\
\hline 20 & 1.0115 & 1.0122 & 1.0114 & 1.0117 \\
\hline 30 & 1.0122 & 1.0121 & 1.0101 & 1.0115 \\
\hline 40 & 1.0114 & 1.0122 & 1.0100 & 1.0112 \\
\hline 50 & 1.0110 & 1.0109 & 1.0104 & 1.0108 \\
\hline 60 & 1.0097 & 1.0106 & 1.0101 & 1.0101 \\
\hline 70 & 1.0111 & 1.0116 & 1.0111 & 1.0112 \\
\hline 80 & 1.0118 & 1.0107 & 1.0110 & 1.0112 \\
\hline 90 & 1.0115 & 1.0115 & 1.0110 & 1.0113 \\
\hline 100 & 1.0100 & 1.0108 & 1.0108 & 1.0105 \\
\hline 110 & 1.0108 & 1.0100 & 1.0103 & 1.0104 \\
\hline 120 & 1.0106 & 1.0102 & 1.0112 & 1.0107 \\
\hline 130 & 1.0112 & 1.0113 & 1.0110 & 1.0111 \\
\hline 140 & 1.0103 & 1.0112 & 1.0110 & 1.0108 \\
\hline 150 & 1.0096 & 1.0107 & 1.0107 & 1.0103 \\
\hline 160 & 1.0099 & 1.0114 & 1.0109 & 1.0107 \\
\hline 170 & 1.0113 & 1.0118 & 1.0112 & 1.0114 \\
\hline 180 & 1.0110 & 1.0111 & 1.0113 & 1.0111 \\
\hline 190 & 1.0118 & 1.0117 & 1.0117 & 1.0117 \\
\hline 200 & 1.0113 & 1.0112 & 1.0118 & 1.0114 \\
\hline 210 & 1.0104 & 1.0115 & 1.0112 & 1.0110 \\
\hline 220 & 1.0109 & 1.0116 & 1.0116 & 1.0114 \\
\hline 230 & 1.0122 & 1.0127 & 1.0125 & 1.0125 \\
\hline 240 & 1.0122 & 1.0131 & 1.0130 & 1.0128 \\
\hline 250 & 1.0136 & 1.0123 & 1.0125 & 1.0128 \\
\hline 260 & 1.0119 & 1.0115 & 1.0117 & 1.0117 \\
\hline 270 & 1.0137 & 1.0124 & 1.0127 & 1.0129 \\
\hline 280 & 1.0127 & 1.0143 & 1.0127 & 1.0132 \\
\hline 290 & 1.0140 & 1.0135 & 1.0139 & 1.0138 \\
\hline 300 & 1.0124 & 1.0126 & 1.0113 & 1.0121 \\
\hline 310 & 1.0125 & 1.0127 & 1.0121 & 1.0124 \\
\hline 320 & 1.0131 & 1.0133 & 1.0124 & 1.0129 \\
\hline 330 & 1.0128 & 1.0143 & 1.0129 & 1.0133 \\
\hline 340 & 1.0118 & 1.0133 & 1.0130 & 1.0127 \\
\hline 350 & 1.0111 & 1.0124 & 1.0116 & 1.0117 \\
\hline Average & 1.0115 & 1.0119 & 1.0115 & \\
\hline
\end{tabular}

Average of 108 data points: 1.0116 
Table 4.2-4. T1000G/RS-14 Ring no. 2 - ID TIR (in.)

\begin{tabular}{|c|ccc|}
\hline Degrees & Top & Middle & Bottom \\
\hline \hline 0 & 0.0009 & 0.0020 & 0.0012 \\
10 & 0.0013 & 0.0024 & 0.0016 \\
20 & 0.0017 & 0.0028 & 0.0019 \\
30 & 0.0019 & 0.0031 & 0.0022 \\
40 & 0.0021 & 0.0032 & 0.0024 \\
50 & 0.0021 & 0.0032 & 0.0024 \\
60 & 0.0020 & 0.0032 & 0.0025 \\
70 & 0.0019 & 0.0031 & 0.0023 \\
80 & 0.0017 & 0.0029 & 0.0021 \\
90 & 0.0014 & 0.0026 & 0.0018 \\
100 & 0.0011 & 0.0023 & 0.0016 \\
110 & 0.0008 & 0.0020 & 0.0013 \\
120 & 0.0005 & 0.0018 & 0.0010 \\
130 & 0.0004 & 0.0016 & 0.0008 \\
140 & 0.0003 & 0.0014 & 0.0007 \\
150 & 0.0003 & 0.0015 & 0.0007 \\
160 & 0.0005 & 0.0017 & 0.0009 \\
170 & 0.0008 & 0.0019 & 0.0011 \\
180 & 0.0011 & 0.0022 & 0.0014 \\
190 & 0.0014 & 0.0024 & 0.0016 \\
200 & 0.0016 & 0.0026 & 0.0018 \\
210 & 0.0018 & 0.0027 & 0.0019 \\
220 & 0.0018 & 0.0028 & 0.0020 \\
230 & 0.0019 & 0.0029 & 0.0021 \\
240 & 0.0019 & 0.0030 & 0.0022 \\
250 & 0.0019 & 0.0030 & 0.0023 \\
260 & 0.0018 & 0.0030 & 0.0022 \\
270 & 0.0016 & 0.0028 & 0.0021 \\
280 & 0.0014 & 0.0025 & 0.0018 \\
290 & 0.0010 & 0.0022 & 0.0015 \\
300 & 0.0006 & 0.0018 & 0.0012 \\
310 & 0.0003 & 0.0016 & 0.0009 \\
320 & 0.0001 & 0.0013 & 0.0007 \\
330 & 0.0000 & 0.0013 & 0.0006 \\
340 & 0.0002 & 0.0014 & 0.0007 \\
350 & 0.0005 & 0.0016 & 0.0009 \\
\hline & & & \\
\hline
\end{tabular}

TIR (108 places): $\quad 0.0032$ 
Table 4.2-5. T1000G/RS-14 Ring no. 2 - OD TIR (in.)

\begin{tabular}{|c|ccc|}
\hline Degrees & Top & Middle & Bottom \\
\hline \hline 0 & 0.0094 & 0.0049 & 0.0022 \\
10 & 0.0093 & 0.0047 & 0.0027 \\
20 & 0.0077 & 0.0042 & 0.0018 \\
30 & 0.0082 & 0.0031 & 0.0013 \\
40 & 0.0073 & 0.0033 & 0.0011 \\
50 & 0.0070 & 0.0028 & 0.0004 \\
60 & 0.0076 & 0.0031 & 0.0000 \\
70 & 0.0077 & 0.0027 & 0.0015 \\
80 & 0.0079 & 0.0027 & 0.0034 \\
90 & 0.0048 & 0.0018 & 0.0019 \\
100 & 0.0048 & 0.0021 & 0.0023 \\
110 & 0.0060 & 0.0017 & 0.0016 \\
120 & 0.0068 & 0.0032 & 0.0021 \\
130 & 0.0080 & 0.0037 & 0.0029 \\
140 & 0.0076 & 0.0043 & 0.0025 \\
150 & 0.0068 & 0.0040 & 0.0029 \\
160 & 0.0075 & 0.0043 & 0.0029 \\
170 & 0.0072 & 0.0037 & 0.0026 \\
180 & 0.0073 & 0.0050 & 0.0022 \\
190 & 0.0072 & 0.0047 & 0.0034 \\
200 & 0.0070 & 0.0043 & 0.0019 \\
210 & 0.0062 & 0.0049 & 0.0026 \\
220 & 0.0076 & 0.0036 & 0.0018 \\
230 & 0.0079 & 0.0051 & 0.0028 \\
240 & 0.0068 & 0.0059 & 0.0042 \\
250 & 0.0084 & 0.0050 & 0.0029 \\
260 & 0.0079 & 0.0045 & 0.0034 \\
270 & 0.0084 & 0.0058 & 0.0039 \\
280 & 0.0105 & 0.0072 & 0.0042 \\
290 & 0.0104 & 0.0058 & 0.0052 \\
300 & 0.0108 & 0.0058 & 0.0044 \\
310 & 0.0102 & 0.0069 & 0.0047 \\
320 & 0.0105 & 0.0061 & 0.0048 \\
330 & 0.0106 & 0.0063 & 0.0046 \\
340 & 0.0113 & 0.0062 & 0.0045 \\
350 & 0.0108 & 0.0054 & 0.0036 \\
\hline & & & \\
\hline
\end{tabular}

TIR (108 places): 0.0113 
Table 4.2-6. T1000G/RS-14 Ring no. 2 - wall thickness (in.)

\begin{tabular}{|ccccc|}
\hline Degrees & Top & Middle & Bottom & Average \\
\hline 0 & 1.0192 & 1.0158 & 1.0123 & 1.0158 \\
10 & 1.0195 & 1.0160 & 1.0132 & 1.0162 \\
20 & 1.0183 & 1.0159 & 1.0127 & 1.0156 \\
30 & 1.0191 & 1.0151 & 1.0124 & 1.0155 \\
40 & 1.0183 & 1.0154 & 1.0124 & 1.0154 \\
50 & 1.0179 & 1.0149 & 1.0117 & 1.0149 \\
60 & 1.0185 & 1.0152 & 1.0113 & 1.0150 \\
70 & 1.0185 & 1.0146 & 1.0127 & 1.0153 \\
80 & 1.0184 & 1.0145 & 1.0144 & 1.0157 \\
90 & 1.0150 & 1.0133 & 1.0127 & 1.0137 \\
100 & 1.0148 & 1.0133 & 1.0128 & 1.0136 \\
110 & 1.0157 & 1.0126 & 1.0118 & 1.0133 \\
120 & 1.0163 & 1.0139 & 1.0120 & 1.0140 \\
130 & 1.0173 & 1.0142 & 1.0126 & 1.0147 \\
140 & 1.0168 & 1.0146 & 1.0121 & 1.0145 \\
150 & 1.0160 & 1.0144 & 1.0124 & 1.0143 \\
160 & 1.0169 & 1.0149 & 1.0126 & 1.0148 \\
170 & 1.0169 & 1.0145 & 1.0126 & 1.0147 \\
180 & 1.0173 & 1.0161 & 1.0124 & 1.0152 \\
190 & 1.0175 & 1.0160 & 1.0138 & 1.0158 \\
200 & 1.0174 & 1.0159 & 1.0126 & 1.0153 \\
210 & 1.0169 & 1.0165 & 1.0134 & 1.0156 \\
220 & 1.0183 & 1.0153 & 1.0128 & 1.0155 \\
230 & 1.0186 & 1.0169 & 1.0139 & 1.0165 \\
240 & 1.0175 & 1.0178 & 1.0154 & 1.0169 \\
250 & 1.0192 & 1.0169 & 1.0140 & 1.0167 \\
260 & 1.0186 & 1.0164 & 1.0145 & 1.0165 \\
270 & 1.0189 & 1.0175 & 1.0149 & 1.0171 \\
280 & 1.0208 & 1.0186 & 1.0150 & 1.0181 \\
290 & 1.0202 & 1.0169 & 1.0156 & 1.0176 \\
300 & 1.0202 & 1.0165 & 1.0145 & 1.0171 \\
310 & 1.0194 & 1.0174 & 1.0144 & 1.0171 \\
320 & 1.0195 & 1.0163 & 1.0144 & 1.0167 \\
330 & 1.0195 & 1.0165 & 1.0141 & 1.0167 \\
340 & 1.0203 & 1.0164 & 1.0141 & 1.0169 \\
350 & 1.0202 & 1.0159 & 1.0134 & 1.0165 \\
\hline \hline Average & 1.0182 & 1.0156 & 1.0133 & \\
\hline & & & & \\
\hline
\end{tabular}

Average of 108 data points: 1.0157 
The average wall thickness of Ring No. 1 is 1.012 in. and the OD TIR is 0.0058 in. The average wall thickness and OD TIR for Ring No. 2 are, respectively, 1.016 in. and 0.0113 in. OD TIR measurements for both rings are higher than the TIR measurements recorded at the ID. Surface roughness and local variations in resin layer thickness are contributing factors, as well as the initial ID TIR of the rings.

\subsection{Composition}

Ring No. 1 was sampled for density and composition at 30 degree intervals around the circumference and at three equally spaced axial locations ("Top", "Middle", and "Bottom") along the ring height. The data are summarized in Table 4.3-1.

Additional density and composition measurements were made of the inner composite layers from the ID to approximately midway through the wall thickness and of the outer composite layers from midway through the wall thickness to the OD. The specimens were taken at four locations at 90 degree intervals from the top portion of the ring. The data provide a measure of the variability through the wall thickness and are summarized in Table 4.3-2.

The average composite density is $0.0605 \mathrm{lb} / \mathrm{in}^{3}\left(1.6756 \mathrm{~g} / \mathrm{cm}^{3}\right)$. The difference between the maximum and minimum value of all density measurements taken from the ring is 0.23 percent. The average composition is 80.36 volume percent fiber, 19.78 volume percent resin, and -0.14 volume percent voids.

The negative voids probably reflect some error in the fiber and/or resin density values that are used in the calculations. Another factor is that the dissolution samples were larger than those usually submitted for nitric acid digestion in order to get a representative cross section of the 1 in. wall thickness. The larger samples took longer to digest and some slight deterioration of the carbon fibers may have occurred. This effect would bias the resin content value high and the void level low. Photomicrographs taken of polished cross sections show that the void level in the composite are negligible, so any slight error in the above factors could cause the voids to be calculated "negative." 
Table 4.3-1. T1000G/RS-14 Ring no. 1 - composition data

\begin{tabular}{|c|c|c|c|c|c|c|}
\hline & \multicolumn{3}{|c|}{ O Degrees } & \multicolumn{3}{|c|}{30 Degrees } \\
\hline & Top & Middle & Bottom & Top & Middle & Bottom \\
\hline \multirow{4}{*}{$\begin{array}{l}\text { Density }(\mathrm{g} / \mathrm{cm} 3) \\
\text { Vol. \% Fiber } \\
\text { Vol. \% Resin } \\
\text { Vol. \% Voids }\end{array}$} & 1.6762 & 1.6761 & 1.6753 & 1.6764 & 1.6768 & 1.6764 \\
\hline & 80.34 & 80.90 & 80.21 & 80.26 & 80.66 & 80.26 \\
\hline & 19.84 & 19.00 & 19.96 & 19.98 & 19.42 & 19.98 \\
\hline & -0.18 & 0.10 & -0.17 & -0.24 & -0.08 & -0.24 \\
\hline & \multicolumn{3}{|c|}{60 Degrees } & \multicolumn{3}{|c|}{90 Degrees } \\
\hline & Top & Middle & Bottom & Top & Middle & Bottom \\
\hline \multirow{3}{*}{$\begin{array}{l}\text { Density }(\mathrm{g} / \mathrm{cm} 3) \\
\text { Vol. \% Fiber } \\
\text { Vol. \% Resin } \\
\text { Vol. \% Voids }\end{array}$} & 1.6768 & 1.6764 & 1.6778 & 1.6759 & 1.6756 & 1.6770 \\
\hline & $\begin{array}{l}80.09 \\
20.26\end{array}$ & $\begin{array}{l}80.35 \\
19.84\end{array}$ & $\begin{array}{l}80.42 \\
19.85\end{array}$ & $\begin{array}{l}80.42 \\
19.70\end{array}$ & $\begin{array}{l}80.31 \\
19.83\end{array}$ & $\begin{array}{l}80.57 \\
19.57\end{array}$ \\
\hline & -0.35 & -0.19 & -0.27 & -0.12 & -0.14 & -0.14 \\
\hline & \multicolumn{3}{|c|}{120 Degrees } & \multicolumn{3}{|c|}{150 Degrees } \\
\hline & Top & Middle & Bottom & Top & Middle & Bottom \\
\hline Density (g/cm3) & 1.6761 & 1.6767 & 1.6751 & 1.6751 & 1.6760 & 1.6750 \\
\hline Vol. \% Fiber & 80.81 & 80.65 & 80.11 & 80.29 & 80.34 & 80.19 \\
\hline Vol. \% Resin & 19.13 & 19.42 & 20.10 & 19.82 & 19.83 & 19.96 \\
\hline \multirow[t]{3}{*}{ Vol. \% Voids } & 0.06 & -0.07 & -0.21 & -0.11 & -0.17 & -0.15 \\
\hline & \multicolumn{3}{|c|}{180 Degrees } & \multicolumn{3}{|c|}{210 Degrees } \\
\hline & Top & Middle & Bottom & Top & Middle & Bottom \\
\hline \multirow{6}{*}{$\begin{array}{l}\text { Density (g/cm3) } \\
\text { Vol. \% Fiber } \\
\text { Vol. \% Resin } \\
\text { Vol. \% Voids }\end{array}$} & 1.6751 & 1.6759 & 1.6777 & 1.6756 & 1.6750 & 1.6731 \\
\hline & 80.01 & 80.33 & 79.95 & 80.31 & 80.29 & 80.19 \\
\hline & 20.24 & 19.83 & 20.55 & 19.83 & 19.82 & 19.80 \\
\hline & -0.25 & -0.16 & -0.50 & -0.14 & -0.11 & 0.01 \\
\hline & \multicolumn{3}{|c|}{240 Degrees } & \multicolumn{3}{|c|}{270 Degrees } \\
\hline & Top & Middle & Bottom & Top & Middle & Bottom \\
\hline \multirow{6}{*}{\begin{tabular}{|l|} 
Density $(\mathrm{g} / \mathrm{cm} 3)$ \\
Vol. \% Fiber \\
Vol. \% Resin \\
Vol. \% Voids
\end{tabular}} & 1.6750 & 1.6752 & 1.6765 & 1.6751 & 1.6743 & 1.6741 \\
\hline & 80.48 & 80.58 & 80.55 & 80.01 & **** & 80.53 \\
\hline & 19.54 & 19.40 & 19.56 & 20.24 & $\star *$ & 19.39 \\
\hline & -0.02 & 0.02 & -0.11 & -0.25 & 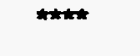 & 0.08 \\
\hline & \multicolumn{3}{|c|}{300 Degrees } & \multicolumn{3}{|c|}{330 Degrees } \\
\hline & Top & Middle & Bottom & Top & Middle & Bottom \\
\hline Density (g/cm3) & 1.6753 & 1.6762 & 1.6752 & 1.6745 & 1.6744 & 1.6752 \\
\hline Vol. \% Fiber & 80.40 & 80.25 & 80.49 & 80.64 & $\ldots$ & 79.92 \\
\hline Vol. \% Resin & 19.68 & 19.97 & 19.54 & 19.25 & 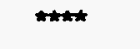 & 20.38 \\
\hline Vol. \% Voids & -0.08 & -0.22 & -0.03 & 0.11 & *t* & -0.30 \\
\hline
\end{tabular}

**** Carbon fibers observed to decompose during dissolution due to slight temperature excursion. 
Table 4.3-2. Composition through wall thickness

\begin{tabular}{|l|c|c|c|c|}
\hline & \multicolumn{2}{|c|}{ O Degrees } & \multicolumn{2}{c|}{ 90 Degrees } \\
\hline & ID & OD & ID & OD \\
\hline Density (g/cm3) & 1.6780 & 1.6719 & 1.6783 & 1.6734 \\
Vol. \% Fiber & 81.09 & 80.05 & 81.10 & 80.12 \\
Vol. \% Resin & 18.88 & 19.92 & 18.88 & 19.94 \\
Vol. \% Voids & 0.03 & 0.03 & 0.02 & -0.06 \\
& \multicolumn{2}{|c|}{} & & \multicolumn{2}{|c|}{} \\
\hline & \multicolumn{2}{|c|}{ 180 Degrees } & \multicolumn{2}{|c|}{ 270 Degrees } \\
\hline & \multicolumn{1}{|c|}{ ID } & OD & ID & OD \\
\hline Density (g/cm3) & 1.6766 & 1.6720 & 1.6776 & 1.6706 \\
Vol. \% Fiber & 81.02 & 79.96 & 81.16 & 79.80 \\
Vol. \% Resin & 18.86 & 20.06 & 18.73 & 20.18 \\
Vol. \% Voids & 0.12 & -0.02 & 0.11 & 0.02 \\
\hline
\end{tabular}

Note: Specimens taken from top of ring. 
Density and composition measurements made of the inner and outer half of the wall thickness show the inner half has a higher average fiber fraction ( 81.09 volume percent) than the outer half (79.98 volume percent). This is consistent with the T1000G/RS-14 cylinder's dry ID that was noted earlier. It is believed that the higher temperature and internal heat source of the mandrel maintained reduced resin viscosity for an extended period, driving additional resin from the ID region during winding. The outer half of the wall thickness is insulated from the internal heat source by the underlying composite to some extent, so that resin bleedout is less from these layers. The composite OD was also left intentionally resin-rich to ensure adequate coverage of the outer fibers.

\subsection{Photomicrographs}

Samples were cut from the top of Ring No. 1 at 90 degree intervals and mounted and polished for examination under an optical microscope. Figures 4.4-1 through 4.4-13 are photomicrographs taken of selected areas that are representative of these specimens.

All the photomicrographs show that the T1000G/RS-14 composite cylinder has a high fiber fraction and relatively few voids. Despite the high fiber packing, the $\mathrm{T} 1000 \mathrm{G}$ filaments in the tow bundle were uniformly coated with the RS-14 resin.

Figure 4.4-1 shows the OD surface resin layer, which is on the order of 0.003 to 0.005 in. thick. Figure 4.4-7 shows a resin-rich layer between two stages resulting from excess resin bleedout during cure of the underlying composite. The resin layer thickness is on the order of 0.0005 to $0.00075 \mathrm{in}$. thick. Figure 4.4-8 shows a relatively dry transition between two stages. Both Figure 4.4-7 and Figure 4.4-8 show there is a slight increase in fiber packing between the initial and final composite layers wound within a stage. This is because the initial layers of each stage basically gain additional compaction from the composite that is wound over it.

Figures 4.4-9 through 4.4-12 are representative of the T1000G/RS-14 cylinder ID. This region was investigated for signs of damage resulting from potential compressive stresses that arise during an elevated temperature postcure as a result of the mismatch in CTE between the steel mandrel and the composite cylinder. Examination of the polished cross sections showed that the ID is continuous and crack-free except for areas where the fiber has been pulled out. The ID is dry and there is only 


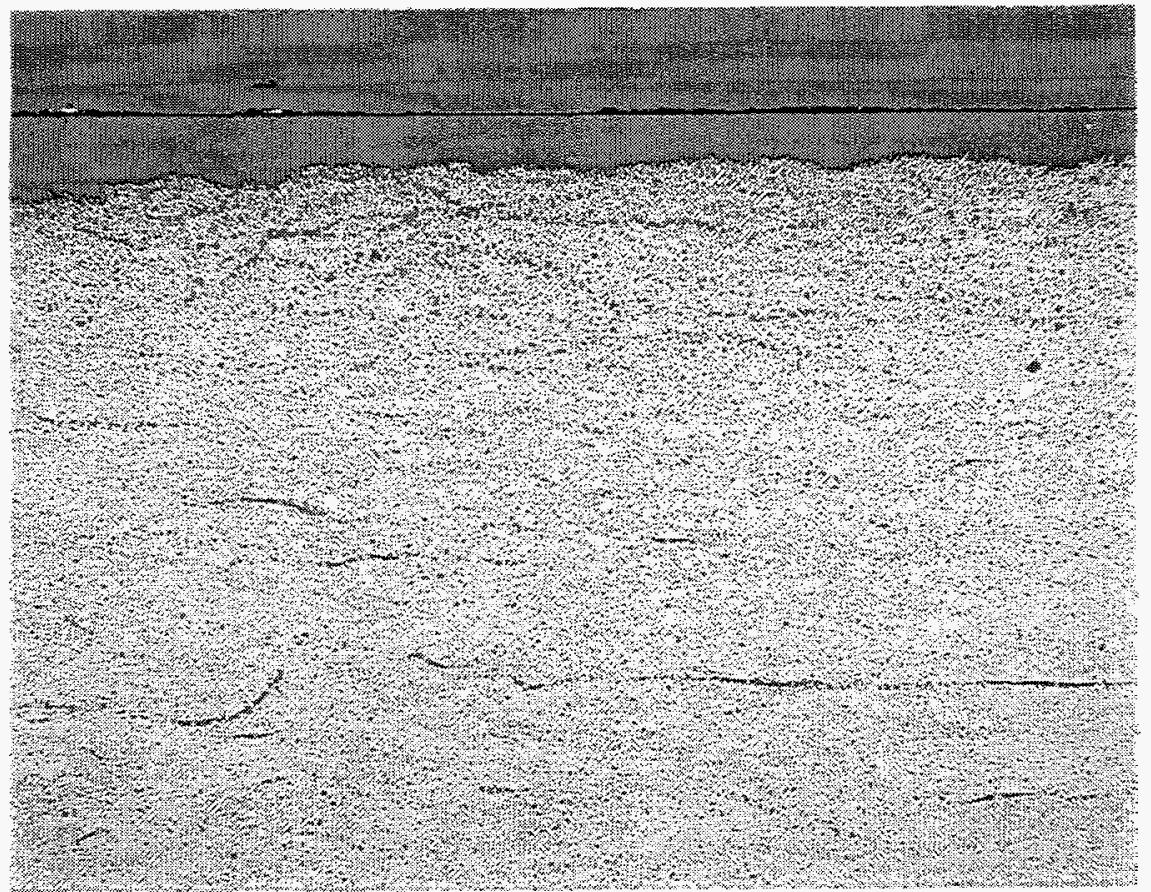

Figure 4.4-1. OD surface resin layer. (80x)

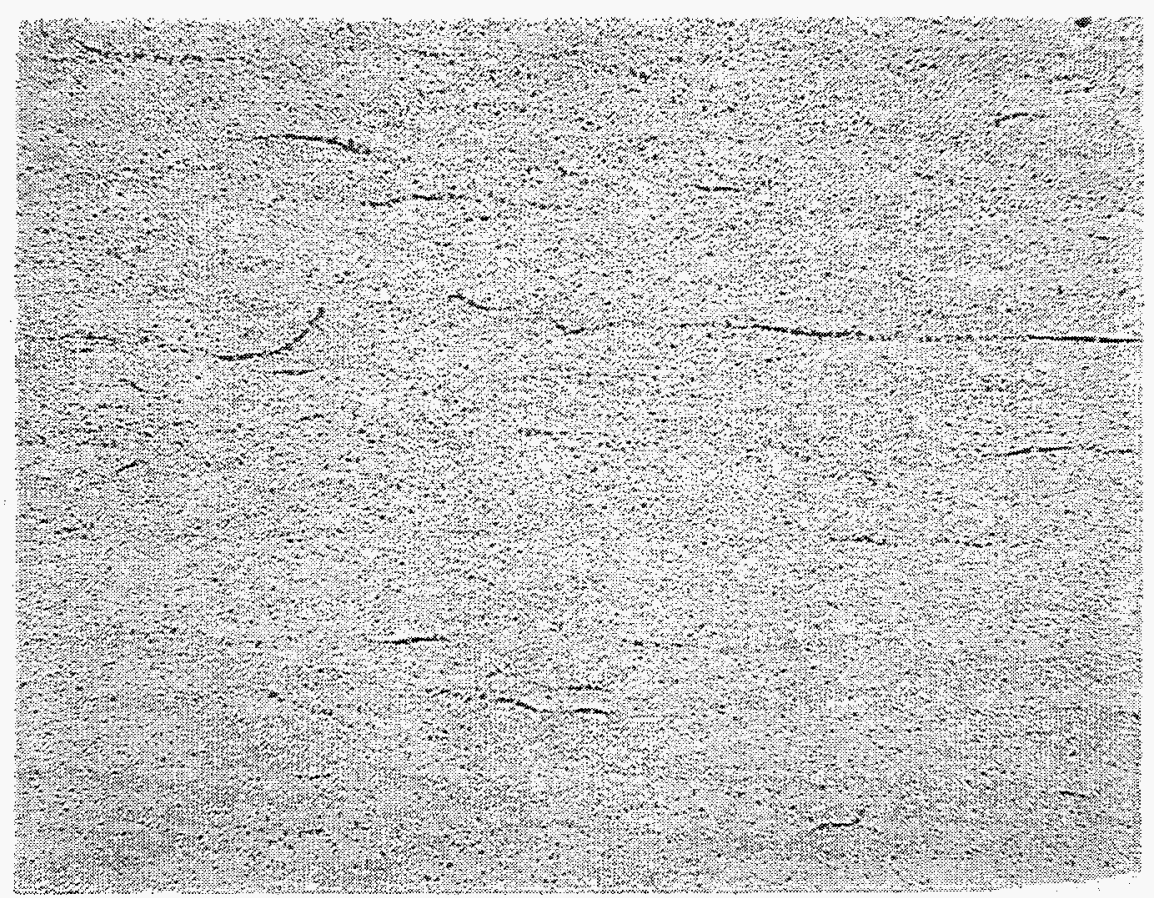

Figure 4.4-2. Composite fiber packing near OD. (80x) 


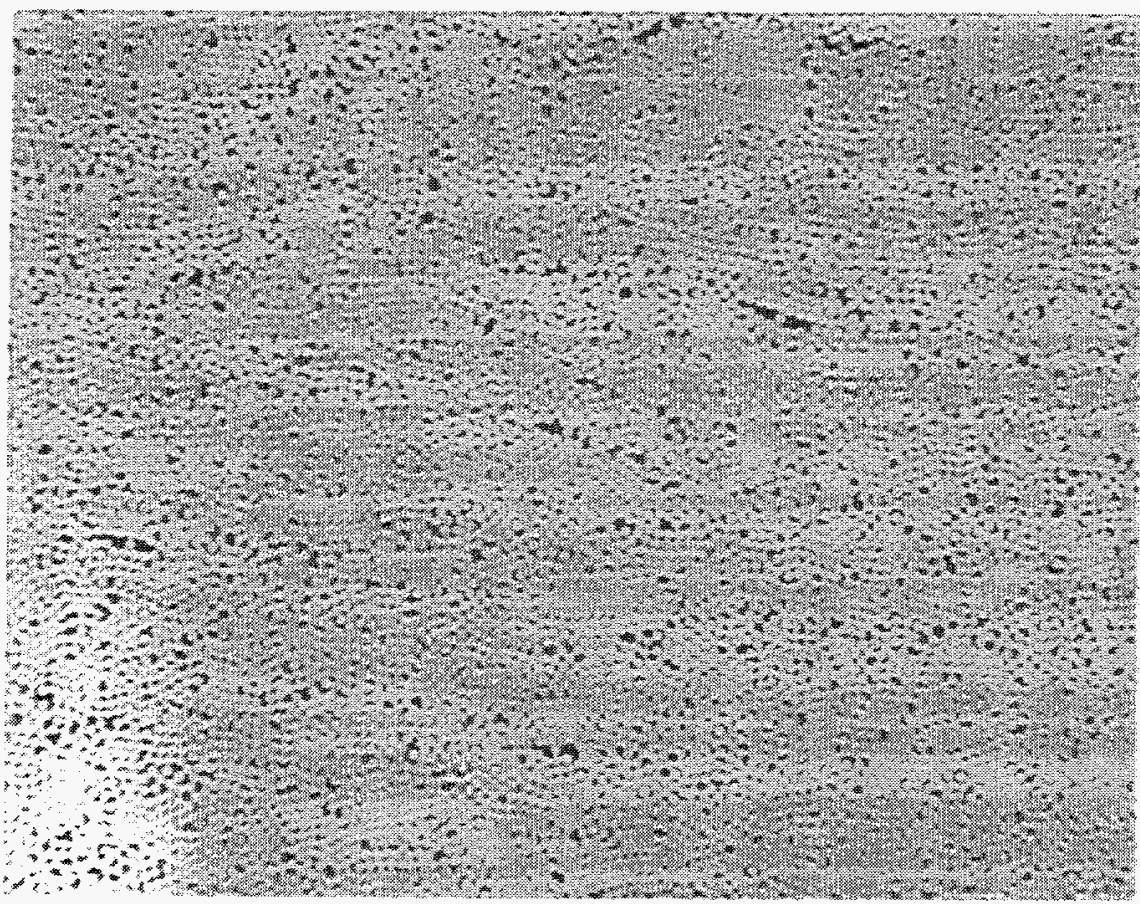

Figure 4.4-3. Composite fiber packing (random location). (200x)

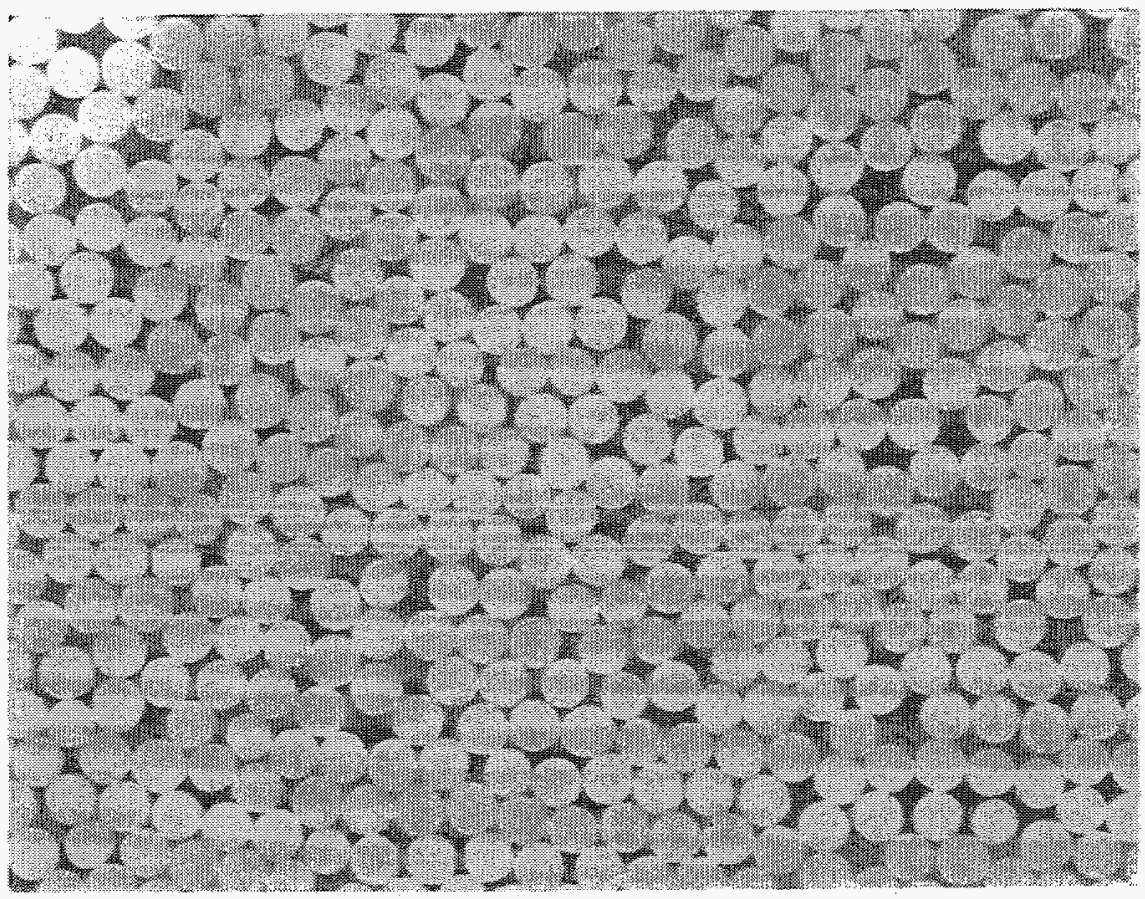

Figure 4.4-4. Composite fiber packing (random location). (1000x) 


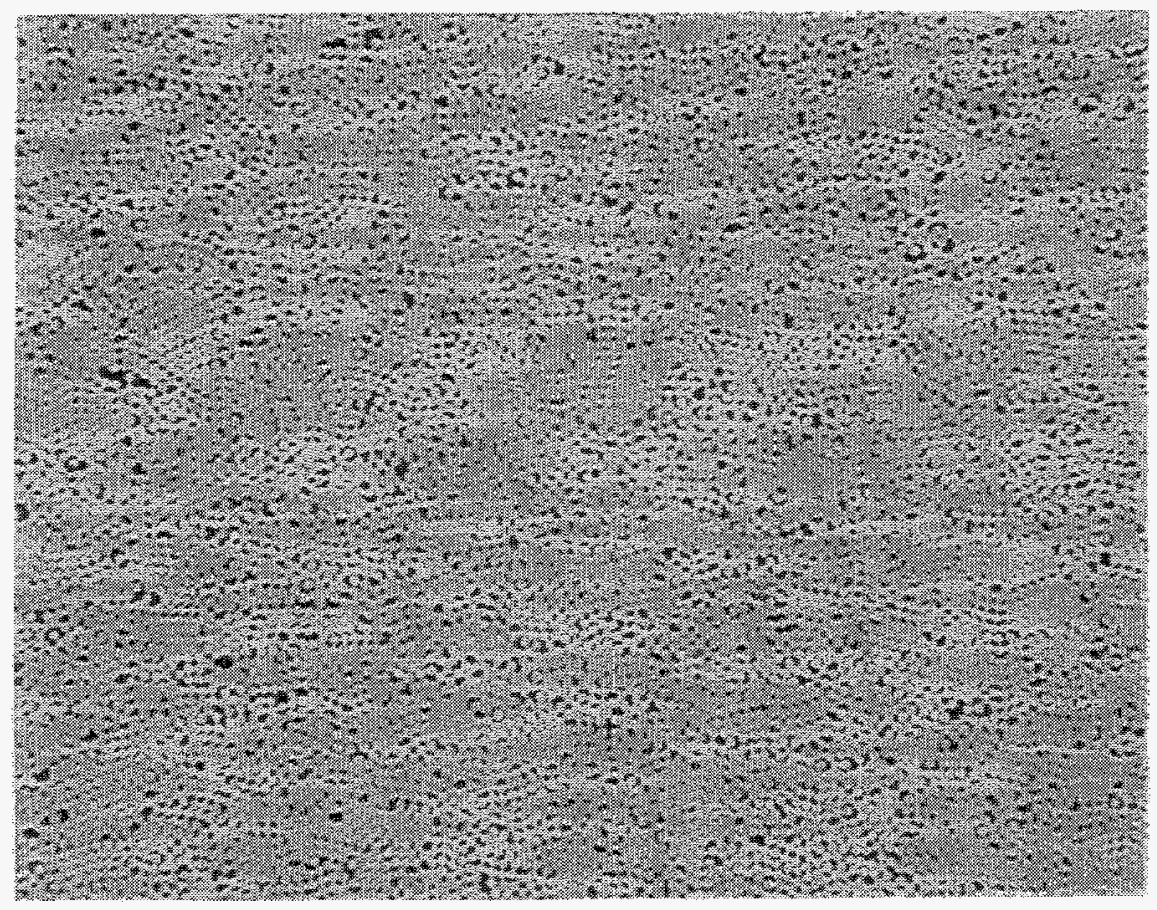

Figure 4.4-5. Composite fiber packing near ID. (200x)

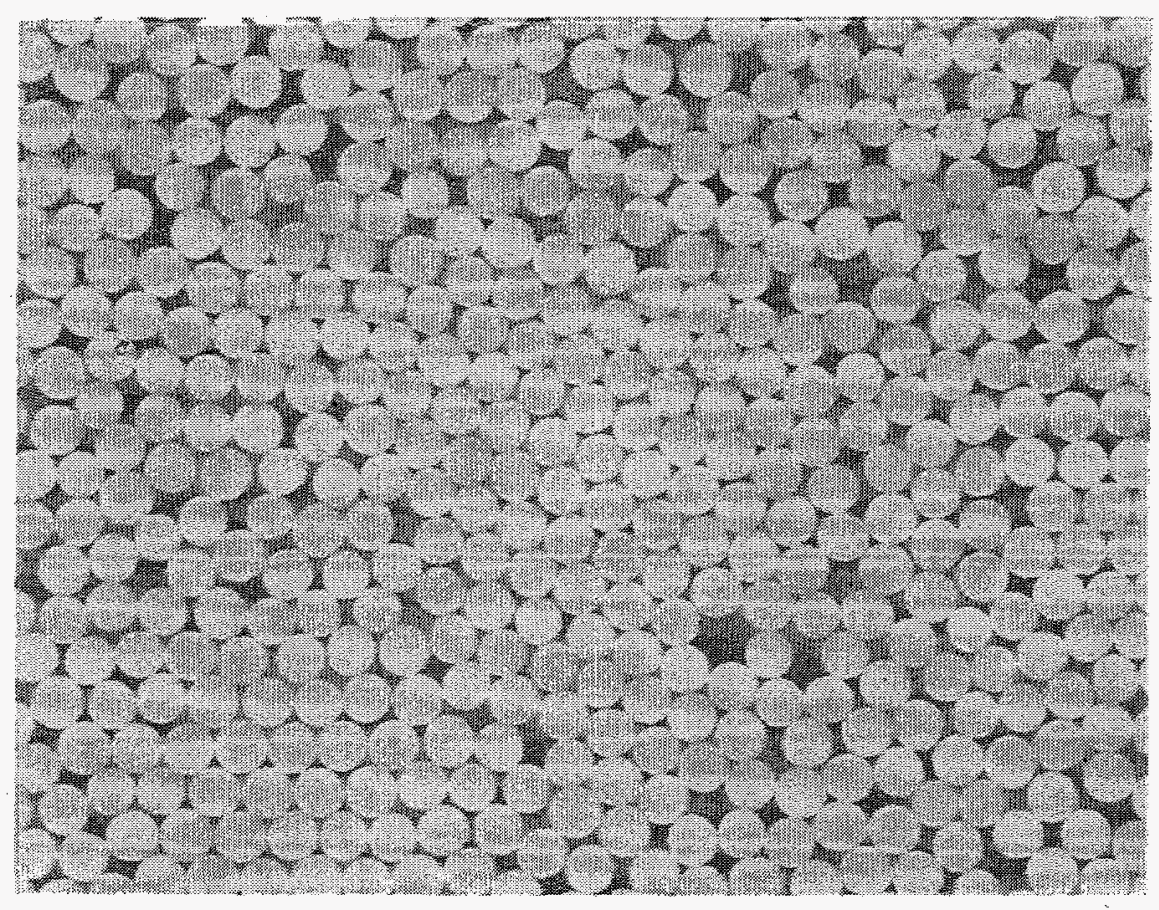

Figure 4.4-6. Composite fiber packing near ID. (1000x) 


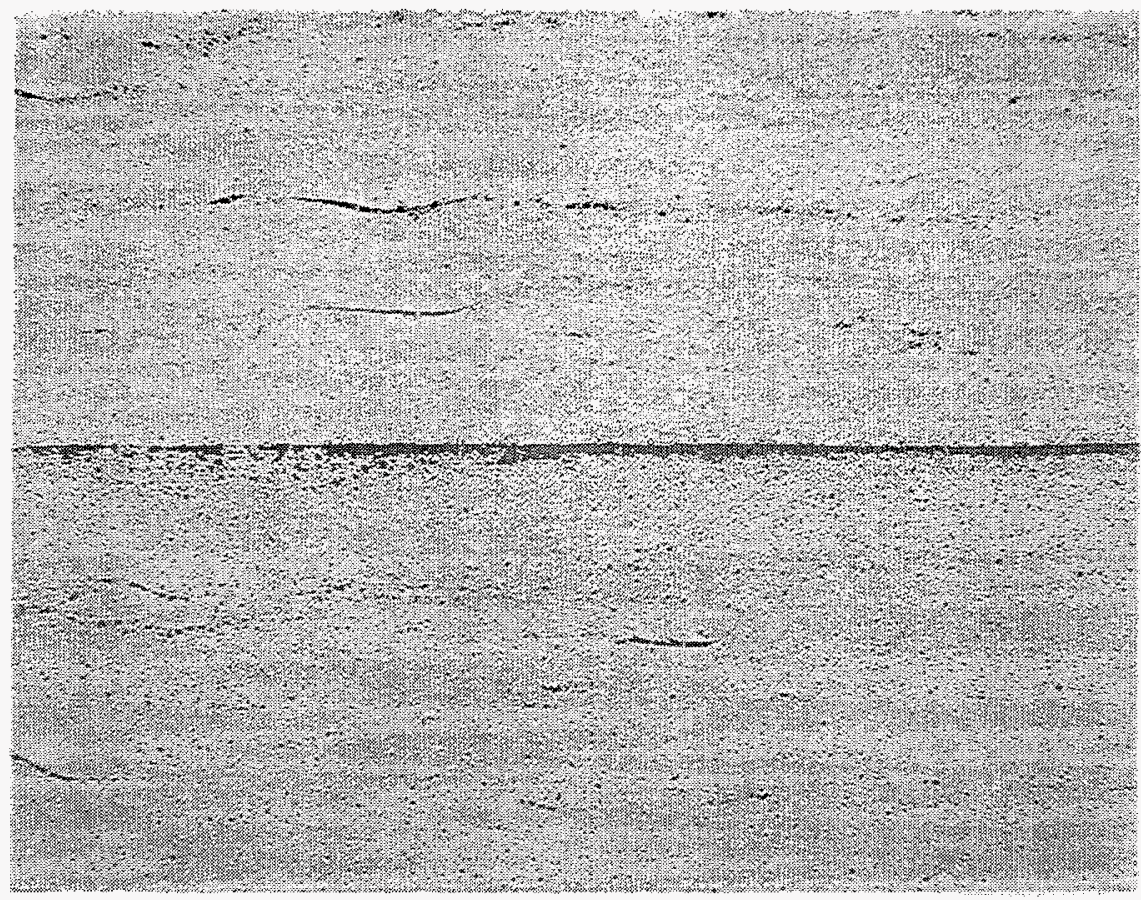

Figure 4.4-7. Resin-rich layer between stages. (80x)

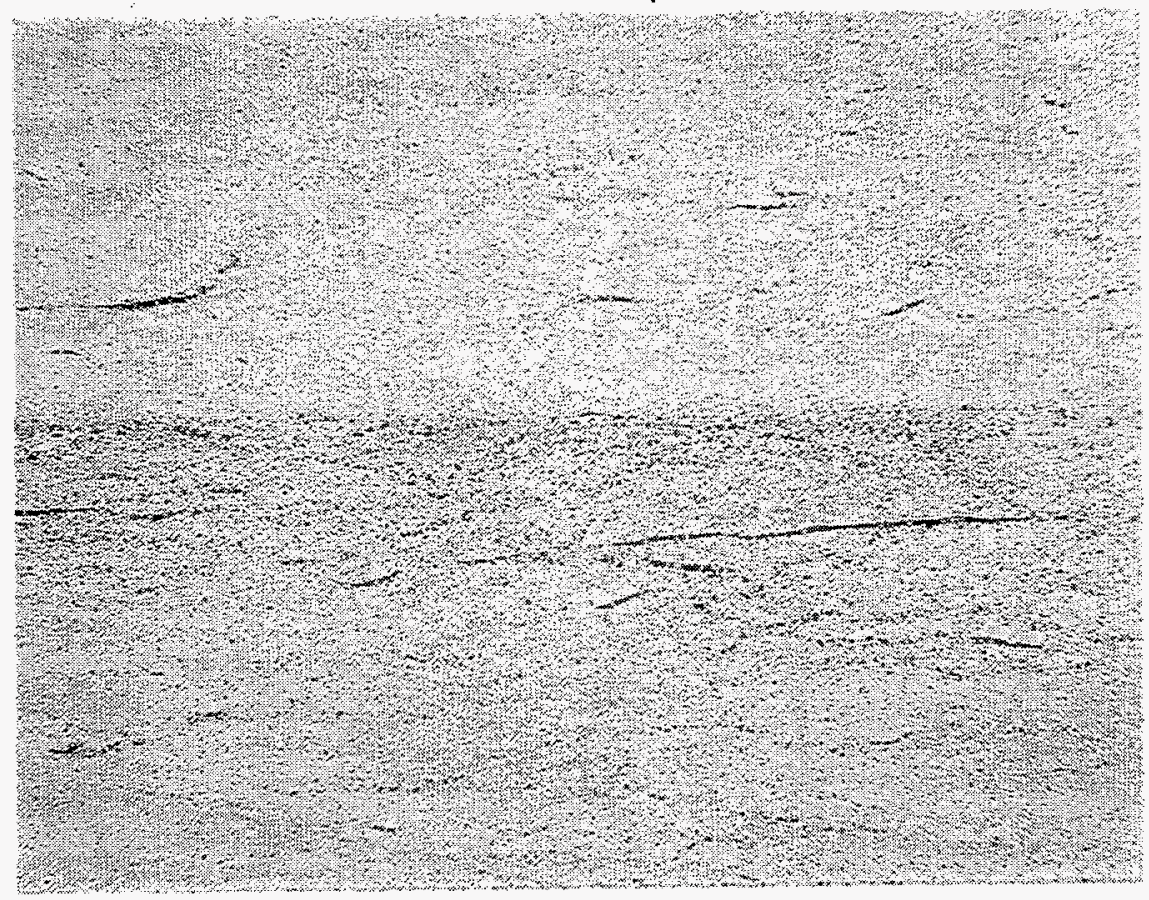

Figure 4.4-8. "Dry" transition between stages. (80x) 


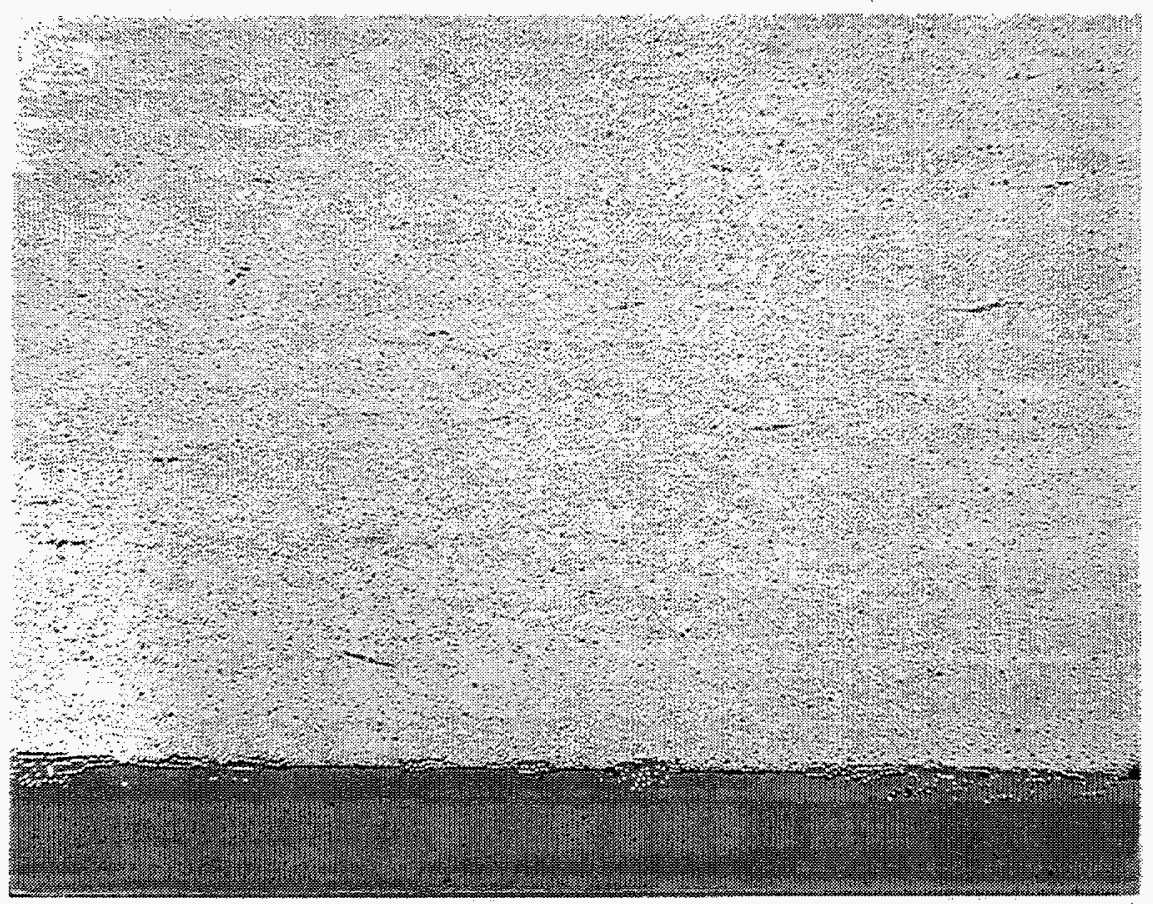

Figure 4.4-9. Composite at ring ID. (80x)

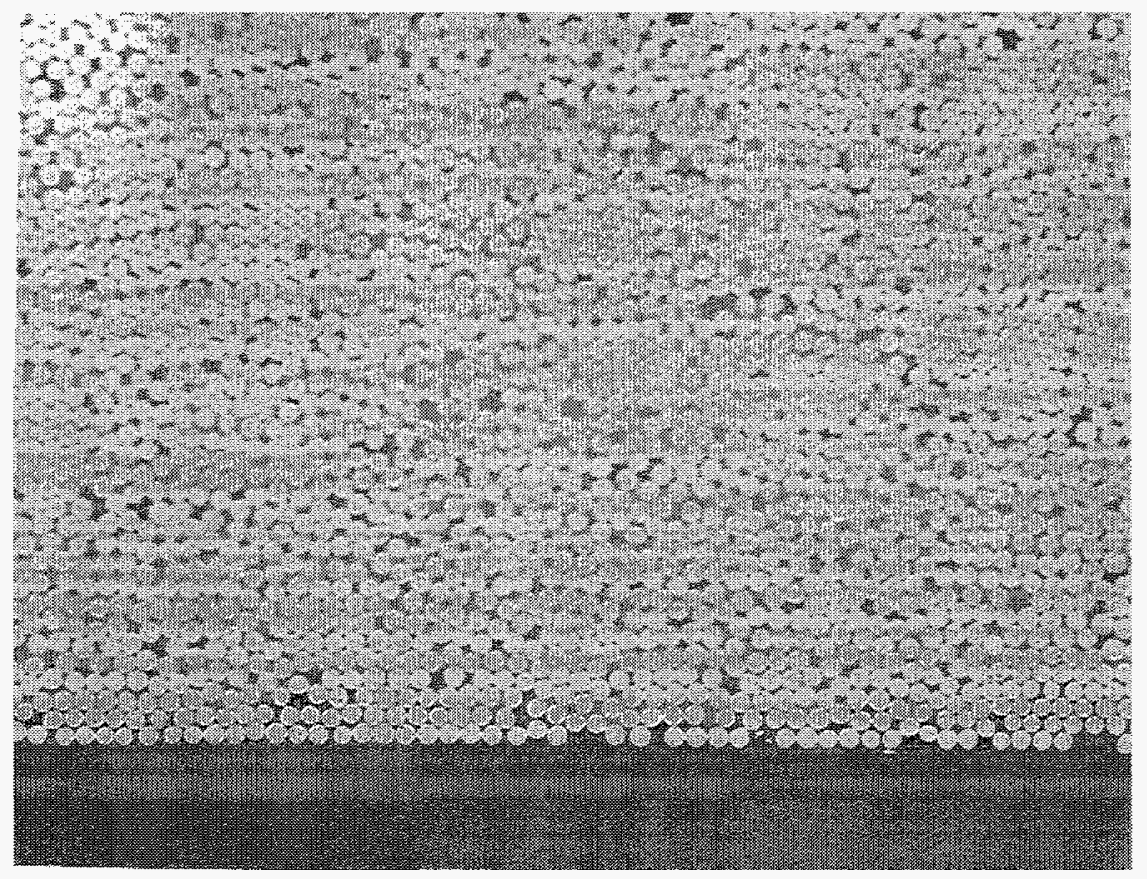

Figure 4.4-10. Composite at ring ID. (400x) 


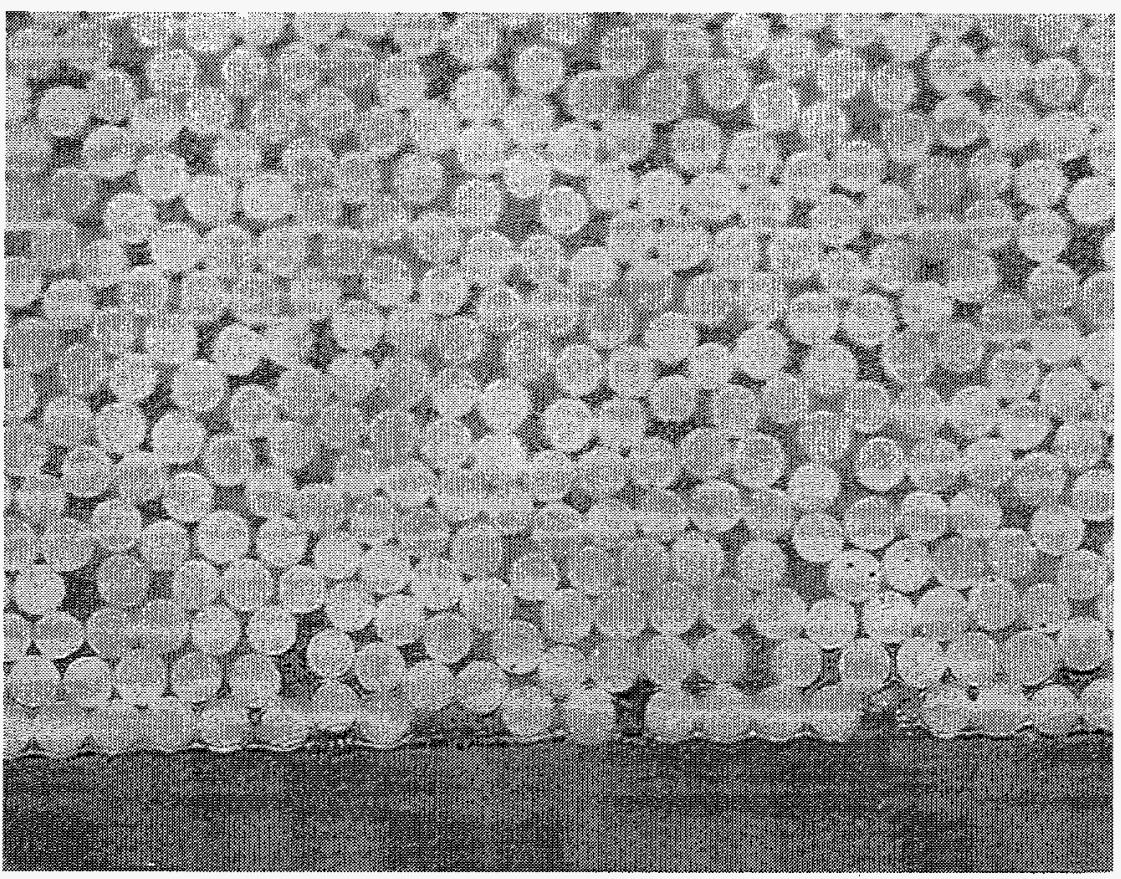

Figure 4.4-11. Detail of ID layer. (1000x)

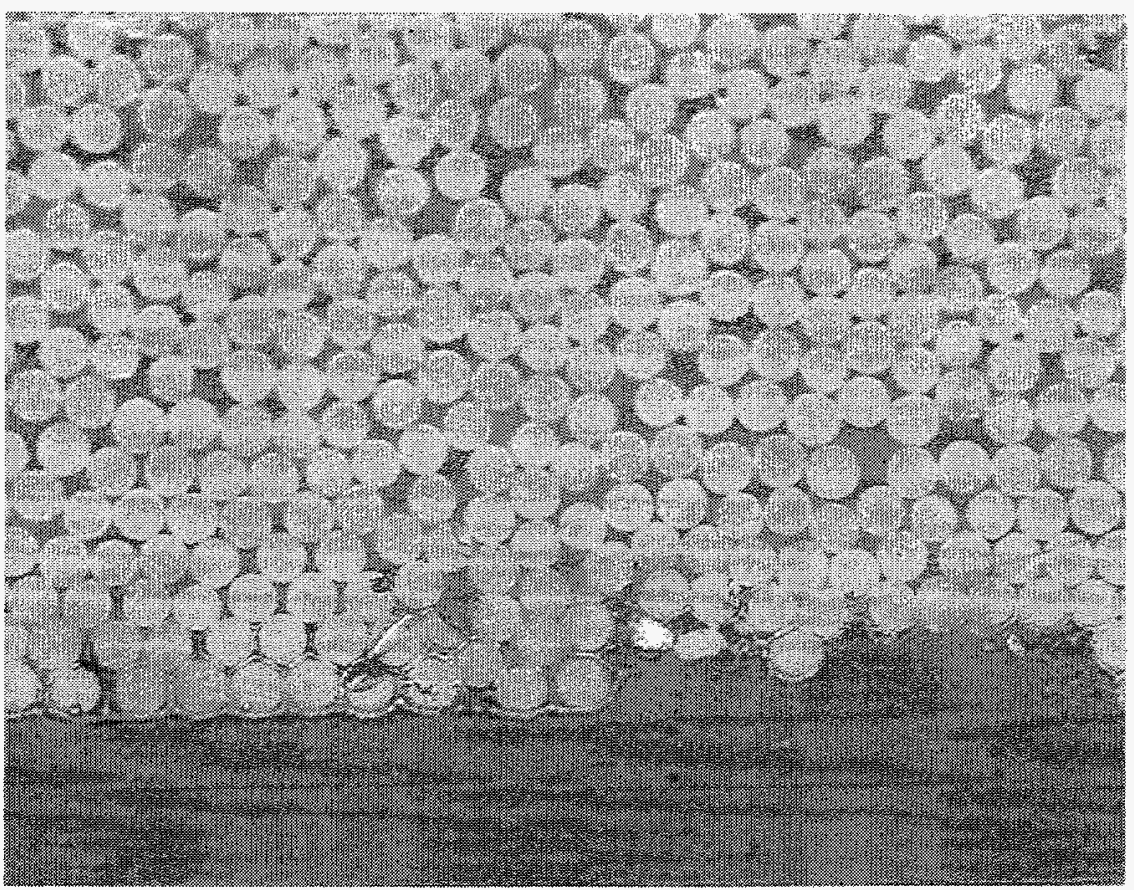

Figure 4.4-12. Detail of ID layer. (1000x) 


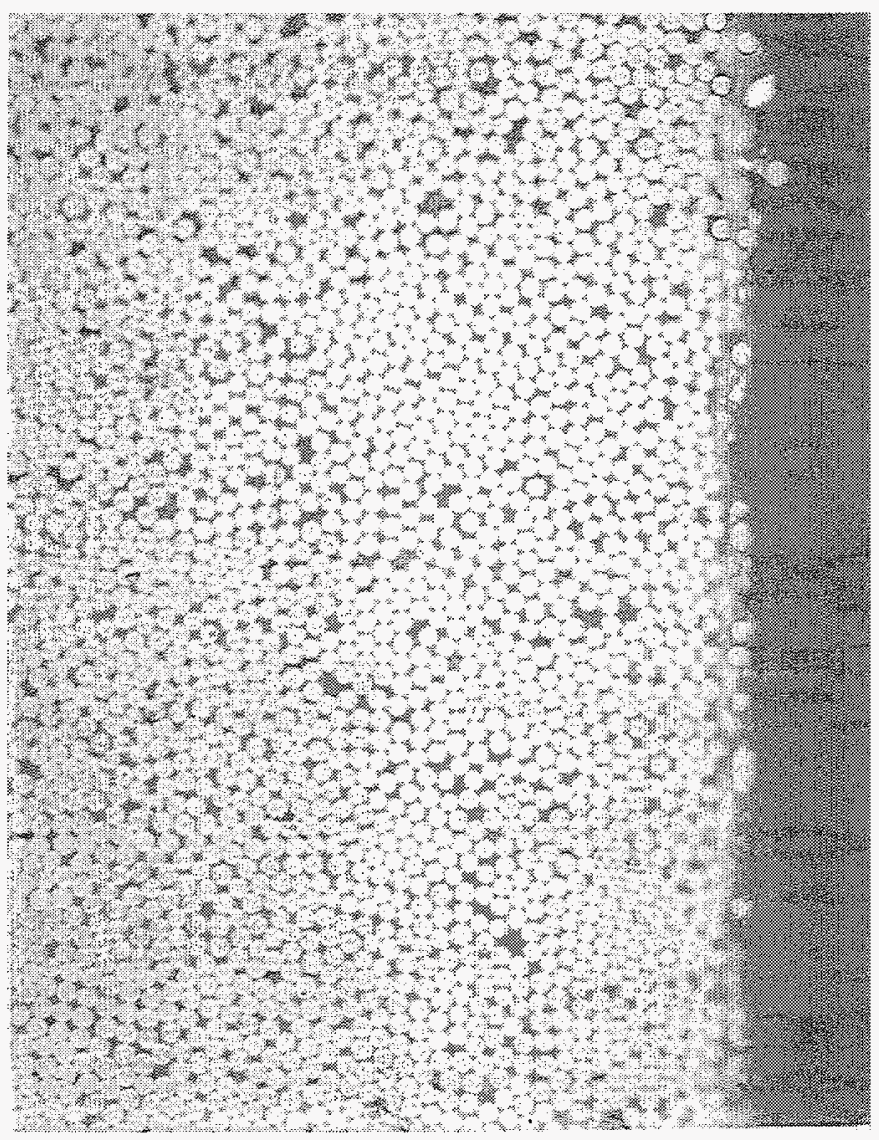

Figure 4.4-13. Detail of ground (cut) edge. (400x) 
a minimal RS-14 resin coating surrounding the ID filaments. There were no cracks visible from the ID extending into the composite. There was a subtle shading or texture difference visible in the resin for approximately two filament diameters ( 10 microns) into the composite that suggest the resin is fractured. However, it cannot be stated definitively that this is not a polishing artifact or due to efforts to focus on the rounded specimen edge.

Figure 4.4-13 is a photomicrograph of an edge that was cut using a diamond-impregnated cutting wheel. It shows that damage to the composite is localized at the surface and does not extend into the bulk composite. This indicates that the T1000/RS-14 composite is reasonably damage tolerant despite its high fiber content.

\section{MANDREL POST-FABRICATION INSPECTION}

The steel mandrel shell was re-inspected to determine whether the thick T1000/RS-14 cylinder fabrication had permanently deformed the mandrel as a result of the winding process and/or the postcure to elevated temperature. Measurements were made using a Cordax coordinate measuring machine for OD TIR at locations every 20 degrees around the circumference and at every 3 in. along the mandrel body length. The data are summarized in Table 5-1.

The mandrel post-fabrication OD TIR is $0.0016 \mathrm{in}$. This compares with the as-manufactured OD TIR of 0.0005 in. of the mandrel. The increase in OD TIR as a result of the composite fabrication is on the order of $0.001 \mathrm{in}$. This indicates that no substantial yielding or deformation of the mandrel occurred as a result of the cylinder fabrication.

\section{ANALYTICAL PROCESS MODEL}

The objective of this activity was to employ an analytical approach to investigate process parameters that impact composite quality and residual stresses in thick composite fabrications.

The T1000G/RS-14 cylinder described in the preceding sections differs from "thin" $1 / 8$ in. wall thickness fabrications because it was wound and cured in nominal $1 / 4$ in. thick stages as opposed to winding and curing the total $1 \mathrm{in}$. wall thickness in one process cycle. This was done partly to avoid overly long winding sessions, but also because it is theorized that stage curing can help reduce undesirable residual stresses in thick composites. 
Table 5-1. Mandrel post-fabrication OD TIR (in.)

\begin{tabular}{|c|ccccccc|}
\hline Degrees & $\mathbf{0}$ & $\mathbf{3}$ & $\mathbf{6}$ & $\mathbf{9}$ & $\mathbf{1 2}$ & $\mathbf{1 5}$ & $\mathbf{1 8}$ \\
\hline \hline $\mathbf{0}$ & 0.0000 & 0.0002 & 0.0005 & 0.0006 & 0.0005 & 0.0008 & 0.0010 \\
$\mathbf{2 0}$ & 0.0001 & 0.0003 & 0.0006 & 0.0004 & 0.0004 & 0.0007 & 0.0009 \\
$\mathbf{4 0}$ & 0.0004 & 0.0004 & 0.0006 & 0.0005 & 0.0004 & 0.0008 & 0.0008 \\
$\mathbf{6 0}$ & 0.0005 & 0.0005 & 0.0007 & 0.0006 & 0.0005 & 0.0008 & 0.0009 \\
$\mathbf{8 0}$ & 0.0007 & 0.0007 & 0.0007 & 0.0007 & 0.0006 & 0.0007 & 0.0008 \\
$\mathbf{1 0 0}$ & 0.0008 & 0.0007 & 0.0008 & 0.0008 & 0.0006 & 0.0007 & 0.0007 \\
$\mathbf{1 2 0}$ & 0.0010 & 0.0008 & 0.0009 & 0.0009 & 0.0007 & 0.0008 & 0.0008 \\
$\mathbf{1 4 0}$ & 0.0012 & 0.0009 & 0.0010 & 0.0010 & 0.0008 & 0.0008 & 0.0008 \\
$\mathbf{1 6 0}$ & 0.0014 & 0.0010 & 0.0011 & 0.0011 & 0.0009 & 0.0010 & 0.0009 \\
$\mathbf{1 8 0}$ & 0.0013 & 0.0010 & 0.0010 & 0.0012 & 0.0010 & 0.0010 & 0.0009 \\
$\mathbf{2 0 0}$ & 0.0011 & 0.0009 & 0.0010 & 0.0011 & 0.0009 & 0.0009 & 0.0010 \\
$\mathbf{2 2 0}$ & 0.0010 & 0.0008 & 0.0009 & 0.0010 & 0.0008 & 0.0010 & 0.0010 \\
$\mathbf{2 4 0}$ & 0.0009 & 0.0008 & 0.0009 & 0.0011 & 0.0009 & 0.0010 & 0.0012 \\
$\mathbf{2 6 0}$ & 0.0007 & 0.0008 & 0.0010 & 0.0011 & 0.0009 & 0.0011 & 0.0013 \\
$\mathbf{2 8 0}$ & 0.0005 & 0.0006 & 0.0008 & 0.0009 & 0.0008 & 0.0010 & 0.0013 \\
$\mathbf{3 0 0}$ & 0.0004 & 0.0005 & 0.0006 & 0.0008 & 0.0007 & 0.0009 & 0.0012 \\
$\mathbf{3 2 0}$ & 0.0002 & 0.0004 & 0.0006 & 0.0006 & 0.0007 & 0.0009 & 0.0016 \\
$\mathbf{3 4 0}$ & 0.0001 & 0.0003 & 0.0006 & 0.0005 & 0.0006 & 0.0009 & 0.0013 \\
\hline
\end{tabular}

TIR (126 places): 0.0016 
During fabrication, the mandrel is heated from room temperature to the winding temperature and a $1 / 4$ in. layer (stage) of resin-impregnated carbon fiber is hoop-wound onto the mandrel. The assembly is then heated to the cure temperature of the resin, at which point the resin system crosslinks, establishing the zero strain state for the resin. Subsequent stages are wound using the same scenario.

When the assembly is cooled to room temperature, the differential thermal expansion between the mandrel, resin, and fiber result in residual stresses in the composite material. Factors that can impact the residual stress state include the fiber tension during winding, the mandrel surface temperature, and the amount of resin migration (bleedout) that occurs from the underlying composite layers during winding and cure, which in turn yields a specific carbon fiber volume fraction in the composite. Other factors include whether or not intermediate stage curing is performed, the stage thickness, the process temperatures (during both winding and cure), and the impact of the mandrel at the composite ID during the postcure cycle.

For these reasons, the residual stress state built into a thick composite is expected to be significantly different than the residual stress state of thin-walled composites. Of particular concern are residual stresses that produce layer interface tension or shear in the material. This study was conducted to provide guidance in establishing fabrication parameters that produce high-quality parts with minimal layer interface residual stresses between stages.

\subsection{Description}

The analytical process model was developed in order to provide insight into issues relevant to the fabrication of thick composite hardware. These include mandrel design, mandrel removal after cure and estimating the magnitude of residual stresses in the composite.

The software package, MathCAD, was used to implement the analytical process model into a PCbased computational package. The model was based upon equating forces and deformations in the radial direction. Only the effects of stiffness and thermal expansion in the hoop direction were considered; the effects of the radial components were assumed to be of secondary importance. This approximation allowed the development of a simple algebraic model. The details of the computations are presented in Appendix A, using the process parameters for the fabrication of the 
T1000G/RS-14 cylinder as an example. The significance of neglecting the radial stiffness and thermal expansion are discussed in Section 6.2.

\subsubsection{Mandrel Design}

The analytical process model was used initially to support the design of the internally heated steel mandrel. When wet-winding quality thick composite hardware, it is important that the mandrel remain cylindrical and that the yield strength of the mandrel material not be exceeded during processing. These measures increase the probability that the cured composite will be dimensionally uniform and that the runout will be minimized; therefore the mandrel was designed to withstand the high compressive stresses that arise from the mismatch in the coefficients of thermal expansion (CTE) between the mandrel material and the hoop-wound composite band during cure.

The analytical process model was used in this study to support the selection of steel over aluminum for the construction of the internally heated mandrel and to set a wall thickness that would minimize mandrel deformation during postcure while still permitting the mandrel to be light enough to be handled at the ORNL/ORCMT facilities. The model estimates that the maximum compressive stresses the mandrel will experience during postcure of a 1 in. thick carbon composite band to $520^{\circ} \mathrm{F}$ to be on the order of $48,000 \mathrm{psi}$. This is significantly lower than the 120,000 to $125,000 \mathrm{psi}$ estimated yield strength of the 4340 steel mandrel shell.

\subsubsection{Mandrel Removal}

The analytical process model was used to predict the interference at room temperature between the cured composite cylinder and the steel mandrel shell to determine if mandrel removal would be difficult. The model predicted that the cylinder ID would be 0.004 in. smaller than the mandrel OD after removal.

In actuality, measurements made of the $T 1000 \mathrm{G} / \mathrm{RS}-14$ cylinder ID showed that it was 0.007 in. larger than the mandrel OD. The easy removal of the mandrel from the composite after cure also showed that the composite ID was slightly larger than the mandrel OD. The discrepancy between the model prediction and experimental results are probably due to simplifying assumptions in the 
analytical model. Some of these are (1) imprecise modeling of the gel/cure process, (2) inelastic deformations that probably occur during the high temperature cure, and (3) relaxation of fiber tension due to resin bleedout.

\subsection{Residual Stresses}

It is probably not possible (or maybe even desirable) to produce a part that contains no residual stresses. The fiber and resin exhibit large differences in their coefficients of thermal expansion (CTE), and their zero strain condition is different. The zero strain state for the fiber is determined by winding tension and the thermal expansion of the mandrel; the zero strain state for the resin is determined by the deformation of the layer at the time crosslinking occurs.

The most significant residual stresses are the layer interface tensile and shear stresses. The stresses are minimal when the average hoop stress in each of the wound stages are equal. One method to accomplish this is to wind each stage with the same tension onto substrates that have the same thermal expansion.

The difficulty with this approach is that the stiffness and the CTE of the substrate upon which each stage is wound is different because of the ever-increasing thickness of the composite stages underneath. As each stage is cured after winding, it contributes to the stiffness when subsequent layers are wound. Also, the wound material restricts the thermal expansion of the mandrel. The stiffness of the substrate affects the strain relaxation that occurs as new material is being wound while the change in thermal expansion affects the diameter on which the material is wound. Thus the thickness, modulus, and CTE of the mandrel, the number and thickness of the stages to be wound, and the internal temperature of the mandrel during winding are additional parameters that affect the residual stresses in the completed ring.

The analytical process model was used to investigate the effect of stage thickness and the mandrel temperature during winding. A series of analyses was performed to evaluate the effect of these parameters and to determine an optimum set of conditions for part fabrication. The results from this study are shown in Table 6.2-1. 
Table 6.2-1. Fabrication options

\begin{tabular}{|c|c|c|c|c|c|c|c|c|c|}
\hline \multirow{2}{*}{$\begin{array}{l}\text { Layer } \\
\text { Thk }\end{array}$} & \multirow{2}{*}{$\begin{array}{c}\text { Mandrel } \\
\text { Temp. }\end{array}$} & \multicolumn{4}{|c|}{ Fiber Stresses } & \multirow{2}{*}{$\begin{array}{l}\text { Matrix } \\
\text { Stress }\end{array}$} & \multicolumn{3}{|c|}{ Layer Interface Stress } \\
\hline & & Inside & 2nd & $3 r d$ & Out & & 1 st & 2nd & $3 r d$ \\
\hline \multirow[t]{3}{*}{ A } & 1 & -8408 & -3083 & 1421 & 5326 & 4408 & -119 & 87 & -45 \\
\hline & 2 & -2372 & -3363 & -1018 & 1935 & 4454 & -20 & -15 & 19 \\
\hline & 3 & -1208 & -1189 & -1201 & -1237 & 4463 & -1 & 1 & 0 \\
\hline \multirow[t]{3}{*}{ B } & 1 & -6806 & -720 & 2670 & 5710 & 4408 & -147 & 153 & -102 \\
\hline & 2 & -2398 & -2019 & -663 & 1452 & 4442 & -32 & 21 & -14 \\
\hline & 4 & -1261 & -1111 & -1172 & -1242 & 4450 & -2 & 4 & -2 \\
\hline
\end{tabular}

\begin{tabular}{ccc} 
& Layer Thickness \\
\hline A: & Layer 1: & 0.25 \\
& Layer 2: & 0.25 \\
& Layer 3: & 0.25 \\
& Layer 4: & 0.25
\end{tabular}

B: Layer 1: 0.4

Layer 2: $\quad 0.2$

Layer 3: $\quad 0.2$

Layer 4: 0.2

\begin{tabular}{llllll}
\multicolumn{5}{c}{ Mandrel Tempertures } \\
\hline 1 & Layer 1: & 175 & 3 & Layer 1: & 175 \\
Layer 2: & 175 & & $\begin{array}{l}\text { Layer 2: } \\
\text { Layer 3: }\end{array}$ & 196 \\
Layer 3: & 175 & & 217 \\
Layer 4: & 175 & & & \\
& & & & \\
& Layer 4: & 238 \\
2 & Layer 1: & 175 & 4 & Layer 1: & 175 \\
& Layer 2: & 200 & & Layer 2: & 201 \\
& Layer 3: & 210 & & Layer 3: & 218 \\
Layer 4: & 215 & & Layer 4: & 235
\end{tabular}


The conditions used to fabricate the thick T1000G/RS-14 composite cylinder provided the baseline conditions for this study; i.e. to wind four layers, 0.25 in. thick, at a constant mandrel temperature of $175^{\circ} \mathrm{F}$. This is identified as layer thickness set $\mathrm{A}$ and mandrel temperature set 1 in Table 6.2-1. The model predicted that this process would produce a compressive hoop stress on the inside of the ring and a tensile stress on the outside. It also predicted a tensile layer interface radial stress in the middle of the ring.

The second combination considered was to wind the first layer thicker than subsequent layers. This should reduce the compression produced by winding the subsequent layers. The first layer was chosen to have a thickness of 0.40 in. while the remaining three layers were 0.20 in. thick. All layers would be wound at a mandrel temperature of $175^{\circ} \mathrm{F}$. This combination (layer thickness set $\mathrm{B}$ and mandrel temperature set 1), produced only a slight improvement in the estimated residual stresses. Varying the winding tension was also examined, but was found to have little effect.

The most effective combination was discovered to be increasing the temperature of the mandrel as subsequent layers are wound. This approach negates the reduction in the effective coefficient of thermal expansion caused by the addition of the layers of composite material. The effect is to maintain a relatively constant mandrel expansion while winding the various layers. A mandrel temperature sequence, temperature set 2 , was utilized in conjunction with both layer thickness sets $\mathrm{A}$ and $\mathrm{B}$. For both cases, a leveling occurred in the residual stress distribution in the ring.

These analyses indicated that the major variable effecting the residual stresses is the temperature of the mandrel during winding. Sets of mandrel temperatures that produce uniform stresses through the thickness of the ring and near-zero radial layer interface stresses between the layers of the ring were calculated for each type of layering. These are the mandrel temperature sets 3 and 4 in Table 6.2-1. The analytical process model predicts that the use of these temperatures during fabrication should result in near-minimal internal residual stresses in the fabricated cylinder.

\subsection{Effect of Simplifying Assumptions}

The analytical process model that was used to calculate the optimum temperature set considered only the stiffness and thermal expansion in the hoop direction; the effects of radial stiffness and 
thermal expansion in the substrate were neglected. An axis-symmetric finite element model was used to obtain an estimate of the significance of ignoring these effects.

From the results of the simplified analysis, observation showed that the minimum residual stresses were produced when the expansion of the substrate was the same as each layer was wound. An axis-symmetric, two-dimensional, finite element model was constructed to solve the following sequence of problems: first, the radial expansion of the bare mandrel was calculated for the specified winding temperature; then the mandrel temperatures required to produce the same radial expansion were computed for the mandrel covered with subsequent layers of composite. This model properly accounts for the effects of radial stiffness and thermal expansion. It neglected, however, the initial deformation caused by the residual stresses of the previously wound layers, the effect of which was accounted for later in the analysis.

The commercial finite element code COSMOS/M was used to do the computations. Four node, asymmetric, orthotropic, iso-parametric elements (PLANE2D) were used to construct a finite element model. The mesh layout is shown in Figure 6.3-1. The y-axis corresponds to the axial direction and the $x$-axis corresponds to the radial direction. Six elements were used in the radial direction for the mandrel and four elements were used for each layer of the composite material. Three elements were used in the axial direction for both materials. To simulate the plane-strain conditions of the long cylinder, the $y$-displacements for nodes along the negative y-surface were set equal to zero while the $y$-displacements along the positive $y$-surface were coupled.

The material moduli used to model the composite material were:

$$
\begin{aligned}
E_{x}=E_{y} & =1.75 \times 10^{6} \mathrm{psi}, \text { and } \\
E_{z} & =33.6 \times 10^{6} \mathrm{psi},
\end{aligned}
$$

and the coefficients of thermal expansions were:

$$
\begin{gathered}
\alpha_{x}=\alpha_{y}=12.0 \times 10^{-6} \text { and } \\
\alpha_{z}=-1.5 \times 10^{-6} .
\end{gathered}
$$




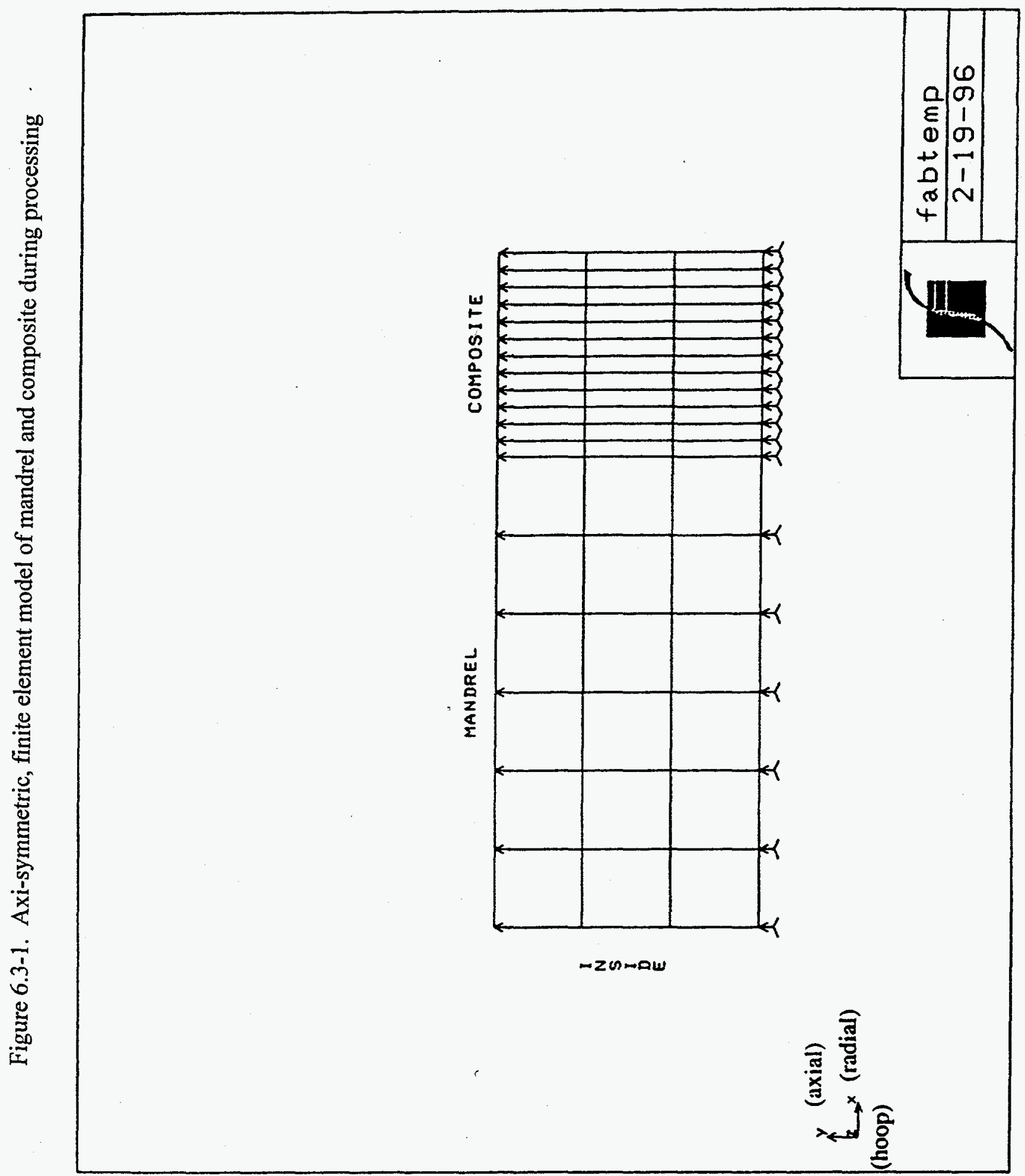


The values for the steel mandrel were:

$$
\begin{gathered}
E=29.0 \times 10^{6} \text { and } \\
\propto=7.5 \times 10^{-6} .
\end{gathered}
$$

When the set of temperatures calculated by the finite element analysis were adjusted to account for the slight difference in the initial deformation, the results differed from those determined by the simplified model by less than 2 degrees. The effect of neglecting the radial stiffness offset the effect of neglecting the radial expansion so that the net effect is negligible.

\section{CONCLUSIONS}

This study has demonstrated that 1 in. thick T1000G/RS-14 polycyanate resin composite can be hoopwound successfully using an internally heated steel mandrel and by stage-curing the composite in $1 / 4$ in. increments. Nominal compositions of 80 volume percent fiber and less than 0.5 volume percent voids were achieved. Density variability around the cylinder circumference and along its width is on the order of 0.23 percent. Fiber, resin and void fraction variability are similarly low.

The cylinder ID TIR is nominally 0.003 in. and is an order of magnitude higher than the mandrel profile tolerance of 0.0005 in. Mandrel deformation during cure and/or composite relaxation after the mandrel has been removed are probable reasons. The cylinder OD TIR is two to three times the ID TIR. In this case, the as-fabricated cylinder surface roughness of an all hoopwound composite is the leading factor. A post-fabrication dimensional inspection of the mandrel shell showed that the shell underwent no significant permanent deformation as a result of the thick carbon fiber cylinder fabrication and its postcure to $520^{\circ} \mathrm{F}$.

When using an internally heated mandrel, some process adjustment is necessary to compensate for the effects of internal versus external heating on the inner composite layers during winding. These adjustments include reducing the mandrel surface temperature and improved temperature regulation. These measures should prevent the ID from being excessively dry as well as reduce composition variability through the wall thickness. Some technique and experience are required as well to adjust surface resin contents at the OD of the intermediate stages and at the final OD. 
The software package, MathCAD, was used to implement an analytical process model to aid in mandrel design and in evaluating the effects of composite fabrication parameters on the residual stresses in thick composite hardware. The model predicts that the major variable effecting the residual stresses is the temperature of the mandrel during winding. Sets of mandrel temperatures that produce uniform stresses through the thickness of the ring and near-zero layer interface stresses between the layers were calculated for the case of a 1 in. thick composite that is wound and cured in $1 / 4$ in. stages. Further work will be required, however, to validate the results of the process model with fabricated hardware. It is also recommended that additional studies be conducted to evaluate analytically and experimentally the impact of residual stresses on the performance of thick composites.

\section{ACKNOWLEDGMENTS}

The authors wish to acknowledge the contributions of J. V. LaForge toward the design of the internally heated steel mandrel and D. Skidmore and K. D. Yarborough for their roles as principal technologists in the cylinder fabrication.

\section{REFERENCES}

1. B. J. Frame and J. M. Starbuck, "Preliminary Investigation of Polycyanate Resins for WetFilament Wound High Strength Composites," SAMPE, Covina, California (1996).

2. B. J. Frame, "Process Study of Polycyanate Resin for Wet-Filament Wound High-Strength Composites," ORNL/TM-13387, Oak Ridge, Tennessee (1997). 
APPENDIX A. Analytical process model applied to T1000G/RS-14 thick cylinder fabrication 
A cylindrical winding mandrel is used to fabricate a fiber-reinforced composite tube. The radius of the mandrel is $r:=12.0$ in and its wall thickness is $t_{\text {mandrel }}:=1.250$. in. The mandrel is fabricated from a steel having a modulus of elasticity of $E_{\text {mandrel }}:=29.0 \cdot 10^{6} \cdot p s i$ and a coefficient of thermal expansion of $a_{\text {mandrel }}:=7.5 \cdot 10^{-6} \mathrm{in} / \mathrm{in} / \mathrm{F}$.

Composite material will be produced by wet-winding a graphite fiber having a modulus of elasticity of $E_{f}:=41 \cdot 0 \cdot 10^{6} \cdot \mathrm{psi}$ and a coefficient of thermal expansion of $\alpha_{f}:=0 \mathrm{in} / \mathrm{in} / \mathrm{F}$. The graphite material will be hoop wound using a winding tension of $F:=12.0 .1 \mathrm{bl}$. The cross-sectional area of the fiber is $A_{f}:=4.2 \cdot 10^{-4} \cdot \mathrm{in}^{2}$. The fiber strain due to the winding tension is given by

Thus

$$
\varepsilon_{w}:=\frac{F}{\left(E_{f} A_{f}\right)}
$$

$$
\varepsilon_{\mathrm{w}}=0.00069 \pi \mathrm{in} / \mathrm{in}
$$

The fiber fraction of the composite material is $v_{f}:=0.78$

The material is wound in a sequence of layers. Each layer is cured before the subsequent layer is wound. The number of layers and their thicknesses are:

$$
\text { nlayer }:=4 \quad \text { thk }:=\left[\begin{array}{l}
0.25 \\
0.25 \\
0.25 \\
0.25
\end{array}\right] \text { in }
$$

Each layer is wound upon a substrate, the properties of which depend upon the properties of the mandrel and all previously wound layers. The thickness of the first substrate is

$$
t_{0}:=t \text { mandrel }
$$

The thickness of subsequent substrates, $i:=1$.. nlayer, are given by

$$
t_{i}:=t_{i-1}+t_{k} k_{i-1}
$$

The mechanical properties of each substrate are equal to the volume weighted average of the properties of the mandrel and the previousily wound layers. The properties of the first substrate are

and

$$
E_{0}:=E_{\text {mandrel }}
$$

$$
a_{0}:=\alpha_{\text {mandrel }}
$$

The properties of the cured resin are $E_{\text {matrix }}:=0.59 \cdot 10^{6} \cdot \mathrm{psi}$ and $\alpha_{\text {matrix }}:=28.0 \cdot 10^{-6} \mathrm{in} / \mathrm{in} / \mathrm{F}$. 
The properties of substrates, $i:=1$.. nlayer, are given by

$$
E_{i}:=\frac{E_{i-1} \cdot t_{i-1}+\left[v_{f} E_{f}+\left(1-v_{f}\right) \cdot E_{\text {matrix }}\right] \cdot t^{\text {th }} k_{i-1}}{t_{i}}
$$

and

$$
a_{i}:=\frac{a_{i-1} \cdot t_{i-1} \cdot E_{i-1}+\left[v_{f} a_{f} E_{f}+\left(1-v_{f}\right) \cdot a_{\text {matrix }} \cdot E_{\text {matrix }}\right] \cdot t_{i-1}}{t_{i} \cdot E_{i}}
$$

Thus

$$
t=\left[\begin{array}{l}
1.25 \\
1.5 \\
1.75 \\
2 \\
2.25
\end{array}\right] \cdot \text { in } \quad \mathrm{E}=\left[\begin{array}{l}
2.9 \cdot 10^{7} \\
2.952 \cdot 10^{7} \\
2.989 \cdot 10^{7} \\
3.017 \cdot 10^{7} \\
3.038 \cdot 10^{7}
\end{array}\right] \cdot \mathrm{psi} \quad \alpha=\left[\begin{array}{l}
7.5 \cdot 10^{-6} \\
6.161 \cdot 10^{-6} \\
5.233 \cdot 10^{-6} \\
4.551 \cdot 10^{-6} \\
4.03 \cdot 10^{-6}
\end{array}\right] \text { in/in/F }
$$

Proir to the winding of each layer, the mandrel is heated from a room temperature of $T_{0}:=65.0 \mathrm{~F}$ to a winding temperature of $T w$, where

$$
\text { Tw }:=\left[\begin{array}{c}
175 \\
175 \\
175 \\
175
\end{array}\right] \text { F. }
$$

The thermal expansion of the substrates, $i:=0 .$. nlayer -1 is

$$
\delta w_{i}:=\alpha_{i} \cdot\left(T w_{i}-T_{j}\right) \cdot r \quad \delta w=\left[\begin{array}{l}
0.0099 \\
0.0081 \\
0.0069 \\
0.006
\end{array}\right] \cdot \text { in }
$$

As each layer is wound, the tension in the fiber produces a radial force that compresses the substrate. The incremental force, $d F$, produced by winding an increment of thickness, $d t$, produces a deformation in the substrate, $\mathrm{d}_{i} \mathrm{~g} \quad$ Equating the force in the winding

$$
\mathrm{dF}:=\mathrm{v}_{\mathrm{f}} \mathrm{E}_{\mathrm{f}} \mathrm{dt} \mathrm{o}
$$

to the force in the substrate,

$$
d F:=\left(t_{i} \cdot E_{i}+v_{f} E_{f} t\right) \cdot \frac{d \delta_{i}}{r} 0
$$

yields

$$
\frac{d \delta_{i}}{d t}=\frac{v_{f} E_{f} \varepsilon_{w} \cdot r}{\left(t_{i} \cdot E_{i}+v_{f} E_{f} t\right)}
$$


The compression of the substrate during the winding of layer $i$ is given by

$$
\delta_{i}:=\int_{0}^{\text {thk }} \frac{v_{f} E_{f} \varepsilon_{w} \cdot r}{\left(t_{i} \cdot E_{i}+v_{f}\right.} \frac{\left.E_{f} s\right)}{s} d s o
$$

or

$$
\delta_{i}:=-\ln \left[1+\frac{v_{f} \text { thk }_{i} \cdot E_{f}}{\left(E_{i} \cdot t_{i}\right)}\right] \cdot r \cdot \varepsilon_{w} \quad \delta=\left[\begin{array}{c}
-0.0017 \\
-0.0014 \\
-0.0012 \\
-0.001
\end{array}\right] \cdot \text { in }
$$

The deformation of the substrate during winding results in a relaxation of the fiber tension. The average fiber strain in layer $i, \varepsilon_{i}{ }^{0}$, is determined by equilibrating the hoop force in the wound material

$$
F_{i}:=v_{f} \text { thk } k_{i} E_{f} \varepsilon_{i}
$$

to the hoop force in the substrate

$$
F_{i}:=t_{i} \cdot E_{i} \cdot \frac{\delta_{i}}{r}
$$

yielding

$$
\varepsilon_{i}:=\frac{t_{i} \cdot E_{i} \cdot \delta_{i}}{v_{f} \text { thk }_{i} \cdot E_{f^{r}}^{r}} \quad \varepsilon=\left[\begin{array}{l}
0.00063 \\
0.000641 \\
0.000648 \\
0.000654
\end{array}\right] \text { in/in }
$$

The combination of thermal expansion and winding tension produces a deformation of

$$
\delta w_{i}:=\delta w_{i}+\delta_{i} \quad \delta w=\left[\begin{array}{l}
0.0082 \\
0.0067 \\
0.0057 \\
0.005
\end{array}\right] \text { in }
$$

After winding, the unit is heated to the curing temperature of $T_{c}:=380 F$. This produces an expansion in the substrate which is resisted by the fiber. The deformation in the substrate, $\delta c_{i} \theta$ is determined by equilibrating the compressive hoop force in the substrate

$$
F:=t_{i} \cdot E_{i}\left[\frac{\delta c_{i}}{r}-\alpha_{i}\left(T_{c}-T_{0}\right)\right]_{0}
$$

to the tensile hoop force in the fiber layer

$$
F:=v_{f} \text { thk }_{i} \cdot E_{f}\left(\frac{\delta c_{i}-\delta w_{i}}{r}+\varepsilon_{i}\right) \text {, }
$$


yielding

$$
\delta c_{i}:=\frac{v_{f} \text { thk } k_{i} \cdot E_{f}\left(\frac{\delta w_{i}}{r}-\varepsilon_{i}\right)+t_{i} \cdot E_{i} \cdot a_{i} \cdot\left(T_{c}-T_{o}\right)}{v_{f} \text { thk } \cdot E_{f}+t_{i} \cdot E_{i}} \cdot r \quad \delta c=\left[\begin{array}{l}
0.0233 \\
0.0196 \\
0.0169 \\
0.0148
\end{array}\right] \cdot \text { in }
$$

The matrix material cures at the temperature $T_{c^{d}}$ therefore, $\delta c_{i}{ }^{\theta}$ corresponds to the zero strain state for the matrix material. Upon return to room temperature the matrix contracts producing tensile stresses in the matrix and compressive stresses in the fiber. The 'free-state' equilibrium deformation in the layer corresponds to a balance of the forces produced by these stresses At room temperature, the hoop force due to the matrix material is

$$
F:=\left(1-v_{f}\right) \cdot t_{i} \cdot E_{\text {matrix }}\left[\frac{\delta o_{i}-\delta c_{i}}{r}-\alpha_{\text {matrix }} \cdot\left(T_{o}-T_{c}\right)\right] 0
$$

The hoop force in the fibers is

$$
F:=v_{f} \text { thk }_{i} \cdot E_{f}\left(\frac{\delta o_{i}-\delta w_{i}}{r}+\varepsilon_{i}\right) \cdot
$$

For equilibrium, the sum of the hoop forces must be zero. Therefore

$$
\delta o_{i}:=\frac{v_{f} E_{f}\left(\delta w_{i}-r \cdot \varepsilon_{i}\right)+\left(1-v_{f}\right) \cdot E_{\text {matrix }} \cdot\left[\delta c_{i}+r \cdot \alpha_{\text {matrix }} \cdot\left(T_{o}-T_{c}\right)\right]}{v_{f} E_{f}+\left(1-v_{f}\right) \cdot E_{\text {matrix }}}
$$

or

$$
\delta 0=\left[\begin{array}{c}
0.0003 \\
-0.0013 \\
-0.0024 \\
-0.0032
\end{array}\right]
$$

In the previous calculations, the initial room temperature deformation of the substrate on which each layer is wound is assumed to be zero, all subsquent deformations are relative to this initial value. Only for the winding of the first layer is the initial deformation of the substrate zero, i.e.

$$
\text { Smandrel }{ }_{0}:=0.0 \text {. in }
$$

The initial room temperature deformation of subsequent substrates $\delta$ mandrel $_{i+1}{ }^{0}$ can be determined by equating the hoop force required to deform the substrate

$$
F:=t_{i} \cdot E_{i} \cdot \frac{\text { mandrel }_{i+1}-\text { smandrel }_{i}}{r}
$$


to the hoop force required to deform layer $i$

$$
F:=\left[v_{f} E_{f}+\left(1-v_{f}\right) \cdot E_{\text {matrix }}\right] \cdot t_{i} \cdot\left[\frac{\delta \text { mandrel }_{i+1}-\left(\text { mandrel }_{i}+\delta_{i}\right)}{r}\right],
$$

Equating yields the room temperture defomation of the mandrel proir to winding each layer

$$
\delta \text { mandrel }_{i+1}:=\frac{t_{i} \cdot E_{i} \cdot \delta \text { mandrel }_{i}+\text { thk }_{i} \cdot\left[v_{f} E_{f}+\left(1-v_{f}\right) \cdot E_{\text {matrix }}\right] \cdot\left(\delta \sigma_{i}+\delta \text { mandrel }_{i}\right)}{t_{i+1}} \cdot \frac{E_{i+1}}{E_{i+1}}
$$

or

$$
\text { Smandrel }=\left[\begin{array}{l}
0 \\
0.0001 \\
-0.0001 \\
-0.0005 \\
-0.0008
\end{array}\right] \cdot \text { in }
$$

After curing of the final layer the unit is subjected to a post cure heat treatment at $T_{p}:=520 \mathrm{~F}$. This produces compressive stresses in the mandrel due to the difference in thermal expansion between the wound material and the mandrel. These stresses are given by

$$
\text { omandrel }:=E_{\text {mandrel }}\left[\left(\alpha_{\text {nlayer }}-\alpha_{\text {mandrel }}\right) \cdot\left(\mathrm{T}_{\mathrm{p}}-\mathrm{T}_{\mathrm{o}}\right)+\frac{\delta \text { mandrel }}{r}\right]
$$

or

$$
\text { omandrel }=-47808 \cdot p s i
$$

The 'free state' defomation of the wound material, after removing from the mandrel, can be determined by equating the negative of the force required to deform the mandrel

$$
F:=-t_{0} \cdot E_{0} \cdot \frac{\delta \text { mandrel }_{\text {nlayer }}-0.0}{r}
$$

to the force required to deform the wound material

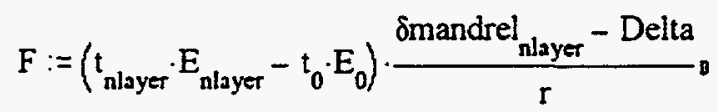

Equating yields

$$
\text { Delta }:=\delta \text { mandrel }{ }_{\text {nlayer }}+\frac{t_{0} \cdot E_{0} \cdot \delta \text { mandrel }}{t_{\text {nlayer }}} \cdot \frac{E_{\text {nlayer }}-t_{0}}{t_{0}} \cdot E_{0}
$$

or

$$
\text { Delta }=-0.00178 \cdot \text { in }
$$


Residual stresses will exist in the wound composite. The residual stresses in the fiber are given by

$$
\text { ofiber }_{i}:=E_{f}\left(\varepsilon_{i}-\frac{\delta w_{i}+\delta \text { mandrel. }}{r}+\frac{\text { Delta }}{r}\right)
$$

while the residual hoop stresses in the matrix are given by

$$
\text { omatrix }_{i}:=E_{\text {matrix }}\left[\frac{\text { Delta }}{r}-\left(\frac{\delta c_{i}+\delta \text { mandrel }_{i}}{r}\right)-\alpha_{\text {matrix }} \cdot\left(T_{o}-T_{c}\right)\right]
$$

Thus

$$
\text { ofiber }=\left[\begin{array}{c}
-8408 \\
-3083 \\
1421 \\
5326
\end{array}\right] \cdot p s i \quad \text { ormatrix }=\left[\begin{array}{c}
3968 \\
4150 \\
4293 \\
4408
\end{array}\right] \cdot p s i
$$

Inner-laminar radial stresses exist between each layer. If oradialo is the radial stress on the inside surface of each layer then

$$
\text { oradial }_{0}:=0.0 \cdot \mathrm{psi}
$$

and for $i:=0 .$. nlayer -2

$$
\text { oradial }_{i+1}:=\frac{\left[v_{f} \text { ofiber }_{i}+\left(1-v_{f}\right) \cdot \text { omatrix }_{i}\right] \cdot \text { th }_{i}}{r}-\text { oradial }_{i}
$$

Therefore

$$
\text { oradial }=\left[\begin{array}{c}
0 \\
-118.59 \\
87.46 \\
-44.64
\end{array}\right] \text { psi }
$$




\section{DISTRIBUTION}

\section{Lockheed Martin Energy Research Corporation}

H. W. Blake

J. L. Cook

J. M. Corum

W. G. Dodge

E. C. Fox

B. J. Frame (20)

R. G. Gilliland

J. G. Hansen (15)

C. J. Janke

J. V. LaForge

R. E. Leach

C. F. Leitten, Jr.

S. R. McNeany

R. E. Norris

F. L. Paulauskas

J. T. Shaffer

J. M. Starbuck

G. E. Wrenn, Jr.

Central Research Library

Laboratory Records - RC

Office of Scientific and Technical Information (2) 